\title{
EL MONASTERIO DE SANTA MARÍA LA REAL DE OIA. ESTUDIO HISTÓRICO-ARTÍSTICO*
}

\author{
Por \\ CARMEN MANSO PORTO
}

\section{RESUMEN}

El bello e inusual emplazamiento del monasterio de Oia a orillas del Atlántico y la asimilación de tres estilos artísticos en su fase más pura y austera le convierten en un monumento emblemático. La autora realiza un estudio de conjunto, que facilitará el trabajo de restauración y conservación del monumento. También se publican varios epígrafes inéditos de la fábrica barroca.

\section{PALABRAS CLAVE}

Monasterio cisterciense, arquitectura, historia, restauración.

* Este estudio histórico-artístico ha sido elaborado por encargo de la Empresa SAITE, del Grupo Banco Pastor, y entregado por la autora el 22 de septiembre de 1999. Fue incluido en el proyecto presentado por el Grupo Banco Pastor a la Xunta de Galicia para rehabilitar el monasterio de Santa María de Oia y reconvertirlo en un Gran Hotel. Además de revisar el texto original, he realizado algunas ampliaciones para esta publicación. Todo ello ha sido posible gracias a la generosidad del Dr. Eduardo Pardo de Guevara, Director del Instituto Padre Sarmiento de Estudios Gallegos.

«CUADERNOS DE ESTUDIOS GALLEGOS», Tomo XLIX, Fascículo 115, Santiago 2002. 


\section{ABSTRACT}

The nice and unusual site of Oia monastery at the shore of the Atlantic Ocean and the assimilation of three artistic styles during their more austere stage, convert it into an emblematic sight. The author carries out an allembracing analysis that will make easier the job of restoration and maintenance of the monument. She, also, divulges different unpublished inscriptions of the baroque building.

\section{KEYWORDS}

Cistercian monastery, architecture, history, restoration.

\section{EMPLAZAMIENTO}

El monasterio cisterciense de Santa María la Real de Oia ofrece un grandioso emplazamiento junto al océano Atlántico, en una ensenada rocosas, entre las villas de A Guardia y Baiona. La llanura litoral en la que se asienta, de privilegiado clima templado, se halla delimitada por el mar a occidente y por los escarpados montes de El Castro y El Cabana a oriente. Varios caminos llegan al monasterio: el del mar, el de la empinada ladera de la montaña al sureste, que comunica con los valles de O Rosal, de Tomiño y del Miño, y la actual carretera de la costa que de norte a sur comunica Baiona con A Guardia. Esta última, en su recorrido, mantiene la traza de la antigua vía romana, salvo en algunos tramos muy próximos al mar, que tuvieron que rectificarse por razones de seguridad. En su trayecto hacia Baiona se han localizado restos de asentamientos romanos - «villa Sursum» en Viladesuso y varios puentes-. Esta vía fue fundamental para el desarrollo económico del monasterio de Oia. El otro camino terrestre, que conduce al valle de O Rosal, fue asimismo frecuentado por los monjes de Oia, que levantaron en ese valle la granja y priorato de San

«CUADERNOS DE ESTUDIOS GALLEGOS», Tomo XLIX, Fascículo 115, Santiago 2002. 
Antonio de O Rosal, que todavía se conserva, además de otras muchas propiedades ${ }^{1}$.

Como ya señaló Ávila y la Cueva en el siglo pasado, el nombre de Oia se relaciona con su emplazamiento. En efecto, «por tener su asiento a orillas de la mar, en una grande profundidad mirada, con respecto a las elevadas sierras que tiene por el oriente, la nombraron Oya, derivado de 'Oyo'» (Fig. 1)2.

La fachada de su templo y las dependencias monasteriales del costado occidental se sitúan al borde del mar. Una robusta muralla y una estrecha carretera, que desemboca en la principal, la separan de la cala, en donde rompen las olas sobre las rocas. Se conservan los restos de un espolón o malecón a pocos metros de la orilla -muy apreciable en bajamar-, cuyos muros se abren en la parte central de la cala y organizaban un pequeño pasadizo con saliente y entrante para los barcos de pesca, que se podía tapar «con una red o empalizada de madera». Se empleaba como sistema de pesca, al quedar allí capturados los peces que habían entrado con la compuerta abierta en pleamar ${ }^{3}$. El recinto portuario, denominado «camboa», protegía las embarcaciones y también amainaba la fuerza y el batir de las olas contra los muros del monasterio. Pese a ello, en los días de fuerte oleaje, el agua salada, arrastrada por el viento, ha causado daños en la sillería, especialmente en la de la fachada del templo y en algunas partes del monasterio. En la orilla del mar embravecido se deposita una gran cantidad de algas pardas -sargazos-, que desde antaño se recogían y todavía se siguen recogiendo con el clamoeiro para el abono de los campos. Al sur, a pocos metros del monasterio, se emplaza el arrabal de la pequeña villa de labradores y pescadores (Fig. 2).

Según un cronista cisterciense de la Congregación de Castilla, el cenobio de Oia es el único de la Orden que se levanta a orillas del Atlántico. Todos los demás se localizan en el interior, en valles y cañadas. Los monjes buscaban lugares tranquilos y desiertos que les permitiesen concentrarse en su vida espiritual y en el trabajo agrícola e intelectual, cumplien-

\footnotetext{
${ }^{1}$ PALLARES MÉNDEZ y PORTELA SILVA, 1971, pp. 69-70; FERREIRA PRIEGUE, 1988, pp. 87-90.

2 ÁVILA Y LA CUEVA, 1995, II, p. 291

${ }^{3}$ ALONSO ROMERO, 1993, p. 138.
} 
do las disposiciones del capítulo general de la Orden de $1134^{4}$. Por su estratégico emplazamiento, los monjes de Oia se tuvieron que ocupar igualmente de la defensa de la costa durante varios siglos, de ahí su denominación de «monjes artilleros» (Figs. 1-2).

A la profunda serenidad que se respira en su entorno contribuyen la preciosa panorámica de la costa, la belleza de la vegetación del recinto -huertas, prado y jardines de sus patios-, el clasicismo y la sobriedad de las dependencias monacales y de la fachada de su templo, renovados en diversos estilos, y también la austeridad del interior del templo, que sigue el modelo más puro y prestigioso del Cister: el creado por su fundador San Bernardo.

Ilustres personajes visitaron el monasterio a lo largo de los tiempos. Uno de las más entrañables acaso sea el pintor pontevedrés Enrique Campo Sobrino en 1909, que pasó allí unas horas dejando un precioso testimonio: la acuarela del conjunto monasterial, realizada desde un alto del costado sur, y sus impresiones sobre el viaje y estancia en el resumen de su diario: «Pasamos en La Guardia la noche y la mañana siguiente; después de ver todo y comer, salimos en un cesto para Oya; trayecto muy solitario pero precioso: llegamos a Oya a las 6 y $1 / 2$, vimos todo el convento e iglesia, hicimos allí noche (bastante malamente). Sobre Oya dicen que hay los restos de un castillo, en un pico muy alto que llaman $O$ Monte do Castelo. A las diez de la mañana del día siguiente salimos en el coche de línea para Bayona» ${ }^{5}$.

\section{HISTORIA}

Los orígenes de Santa María de Oia no están muy claros. Algunos autores del siglo XVII lo suponen fundado por San Martín Dumiense en 569. Para otros fue San Fructuoso de Braga en la primera mitad del siglo VII. Pero ambos relatos legendarios carecen de fundamento histórico y así también lo indicó el autor del llamado tumbo pequeño, escrito en 1739, que remonta su existencia al primer tercio siglo XII y la vincula con va-

${ }^{4}$ TORRES BALBÁS, 1954, p. 19.

${ }^{5}$ FILGUEIRA VALVERDE, 1944, p. 163. 
rios privilegios otorgados por el monarca Alfonso VII, aunque algunos autores (Rassow y Sánchez Belda) han sospechado de la falsedad de estos pergaminos, conservados en el Archivo Histórico Nacional ${ }^{6}$. De las dos leyendas y de los documentos reales se ocupa extensamente el mencionado tumbo en el primer capítulo, que dedica a la «fundación y principios del monasterio». Allí se atribuye al monarca Alfonso VII, basándose en los citados privilegios reales ${ }^{7}$. Esta tradición dejó asimismo huella en un epígrafe pintado al fresco, que todavía se conserva, muy deteriorado, en el arco triunfal de la iglesia y reza así: «El Emperador don Alonso, Rey de España y Fundador de este Monasterio. Don Sancho el Deseado, fundador de Calatrava y bienhechor de esta Casa». De esta misma tradición sobre su fundación a mediados del siglo XII se hacen eco fray Prudencio de Sandoval $(1610)^{8}$ y el P. Enrique Flórez $(1767)^{9}$, que también mencionan algunos documentos de Alfonso VII.

El primer indicio de la existencia de Oia se halla, pues, en un privilegio (Tui, 26-VI-1137) otorgado por el monarca Alfonso VII, en el que dona al monasterio de Oia y a su abad don Pedro la mitad de las iglesias de Erizana (Baiona) y A Guardia, y todas las de Mogaes, Pedornes, Burgueira, Loureza y O Rosal. Al día siguiente concedía la villa de Erizana a la iglesia de San Cosme y San Damián y a su prior don Pelayo y a sus ermitaños. Por otro documento, muy dudoso por su fecha, otorgado en Zamora el 27 de junio de 1130 (1140, según el tumbo pequeño y entre 1135-38 según Sánchez Belda), el Rey otorgaba a don Pedro, «abad de Oia», y a sus monjes lo que pertenecía al poder Real en tierra de Toroño: la ermita de San Cosme con sus cotos y las villas de Erizana y Varedo, con los términos y derechos que se indican. En un cuarto privilegio (Sahagún, 17-IV-1139), el monarca donaba a Oia el monasterio de San Mamede de Loureza, con sus términos y dos villas ${ }^{10}$. En el de don Pelayo, obispo de Tui (19-IV-1145), se cede al abad Pedro y a sus monjes los derechos episcopales del monasterio de San Mamede de Loureza; en él se

${ }^{6}$ SÁNCHEZ BELDA, 1953, pp. 110-111 (con la cita de Rasow).

${ }^{7}$ Tumbo pequeño, en AMEAL GONZÁLEZ, 1949, pp. 116-118; 1950, pp. 19-22, 83-85.

${ }^{8}$ SANDOVAL, 1610, p. 120.

${ }^{9}$ FLÓREZ, 1767, pp. 22-23.

${ }^{10}$ SÁNCHEZ BELDA, 1953, pp. 107-111.

«CUADERNOS DE ESTUDIOS GALLEGOS», Tomo XLIX, Fascículo 115, Santiago 2002. 
cita a Oia como una villa propiedad de ese monasterio, lo que indica la prioridad de Lourenzá sobre Oia. Además no se menciona la existencia de monjes ni del supuesto monasterio o eremitorio de Oia, lo cual plantea más problemas sobre sus orígenes.

Del contenido de estos privilegios, de cuya autenticidad se viene dudando, aunque su posible falsificación parece sugerir que entonces ya hubiese monjes en $\mathrm{Oia}^{11}$, y de acuerdo con el autor del mencionado tumbo pequeño, cabe pensar en la existencia de tres comunidades diferentes: la de Oia con su abad Pedro, la de San Cosme y San Damián, cerca de Baiona, con su prior Pelayo y sus ermitaños, y la de San Mamede de Loureza, en la cabecera del valle de O Rosal, con sus monjes negros. Todos ellos, que seguían la regla de San Benito, se reunían en Oia los días de fiesta para «reconciliarse y conferenciar de las virtudes y aprovechamiento en la vida espiritual», además de informar al abad don Pedro de lo que ocurría en sus respectivas comunidades ${ }^{12}$. Antes de 1149 , las tres se habían fusionado en el monasterio de Oia, bajo la observancia de la Regla de San Benito. En efecto, el 23 de abril del mencionado año, el monarca Alfonso VII concedía a su abad Pedro y a los monjes de Oia todo lo perteneciente al poder real en Mougás, Viladesuso y Pedornes. Este proceso fundacional, a partir de la unión de varias comunidades o grupos eremíticos en una sola de monjes benedictinos bajo la Regla de San Benito, supone una evolución hacia el monaquismo, muy frecuente por estos años en la Península Ibérica ${ }^{13}$.

Los cuatro primeros abades, con don Pedro Inicio a la cabeza, fueron benedictinos, pero en 1185, según ha señalado el P. Manrique y al que siguen todos los historiadores, el monasterio se incorporó a la Orden del Císter, integrándose en la filiación de Clairvaux, el cenobio borgoñón fundado por San Bernardo, al que también se afiliaron los demás gallegos ${ }^{14}$.

El tumbo de 1739 también se ocupa «del lugar o sitio de Oia antes de la fundación del Monasterio y de las causas de éste». Interesa sobre todo por el contenido de algunos relatos, como el de la higuera con frutos maduros, que todavía mantiene vivos la tradición. Al parecer, el lugar de

\footnotetext{
${ }^{11}$ VALLE PÉREZ, 1982, p. 275.

${ }^{12}$ Tumbo pequeño, en AMEAL GONZÁLEZ, 1950, p. 160.

${ }^{13}$ VALLE PÉREZ, 1982, p. 275.

${ }^{14}$ Ibídem, p. 275.
} 
Oia fue «castillo o fortaleza que ocuparon algún tiempo los moros». Cuando éstos se fortificaron en el monte de Santa Tecla, los cristianos, que se defendían en el castillo de Oia, hicieron una tregua con ellos, a causa del invierno, y acordaron que cuando brotasen los higos nuevos, los moros les entregarían la plaza o lucharían por ella. Éstos esperaban la llegada de refuerzos de África. Pero, a mediados de febrero, una higuera, que crecía «en el foso del castillo de Oia», dio frutos maduros. Los cristianos llevaron un ramo a los moros y éstos, asombrados, cumplieron su pacto, entregando el castillo y trasladándose a Portuga ${ }^{15}$.

Al parecer, el tumbo grande, iniciado hacia 1700 y con ampliaciones hasta 1832, habla de una ermita de Nuestra Señora, que levantarían los cristianos para celebrar su triunfo, y ésta sería «la primera habitación de los monjes de Oia» ${ }^{16}$. Allí se reunirían las tres comunidades antes de su fusión, y quizás en ese mismo lugar se levantase el nuevo monasterio. Pero el autor del tumbo pequeño (1739) supone que este emplazamiento no era «acomodado ni apto para fortaleza o castillo», habiendo en sus alrededores lugares más elevados, como el que supone el más idóneo: «el montecillo que hay inmediato y enfrente de la entrada y puerta del soto o bosque, en cuya cima se ve una pequeña llanura, y en toda su circunferencia, al resbalar, vestigios de muralla o pared gruesa, que entonces se llamaba el Castriño o Castillo» ${ }^{17}$. Sobre los restos del castillo en el mismo lugar tenemos el testimonio más reciente de Enrique Campo en el diario de la mencionada excursión $(1909)^{18}$.

Con estos relatos se relaciona el escudo de armas del monasterio de Santa María de Oia, cuartelado, del que se conservan varios ejemplares esculpidos y pintados. El más antiguo de los esculpidos, del siglo XVI, se localiza en la enjuta izquierda del arco que soporta el coro alto de la nave de la iglesia. Otros tres, del siglo XVIII, también cuartelados, pero timbrados con Corona Real, se localizan en la fachada de la misma iglesia, en una lápida de una capilla de la iglesia parroquial de San Mamede de Pedornes, que perteneció al monasterio de Oia, con el epígrafe: «Esta

\footnotetext{
${ }^{15}$ Tumbo pequeño, en AMEAL GONZÁLEZ, 1950, pp. 159-163.

${ }^{16}$ Citado en tumbo pequeño, 1950, p. 160.

${ }^{17}$ Tumbo pequeño, en AMEAL GONZÁLEZ, 1950, pp. 159-163.

${ }^{18}$ FILGUEIRA VALVERDE, 1944, p. 163.
} 
capilla es de el R. Pr. ${ }^{e}$ de Hoia. Reedificose año $1736 »^{19}$. El tercero se halla en la capilla del antiguo priorato y granja de San Antonio de O Rosal, hoy cementerio parroquial ${ }^{20}$. Hay además constancia de la existencia de dos candelabros de madera dorada con las armas del monasterio, cuyo paradero desconozco, y seguramente se trate de una pintura ${ }^{21}$. De la misma época se conservan otras piezas heráldicas, pintadas en los lienzos murales de la capilla mayor de la iglesia y en un libro manuscrito de privilegios reales ${ }^{22}$. El báculo abacial con mitra del primer cuartel alude a su unión a la Orden cisterciense, que se halla vuelto hacia fuera, refieriéndose a su jurisdicción temporal y espiritual. Según el tumbo grande, la letra «A» -repetida nueve veces- del segundo cuartel recuerda «a los nueve Reyes Alfonso que ayudaron a sus fundaciones, dotaciones y uniones», pero el autor del tumbo de 1739 no alcanza a entender el significado de este cuartel. El ramo de higuera con frutos maduros del tercer cuartel rememora el milagro de la higuera del foso de Oia -en el jardín del monasterio todavía se conservan varias higueras-. El castillo del cuarto cuartel alude a la fortaleza o también a la batería, «que siempre ha habido y persevera hasta el presente tiempo, al frente y dentro de la portería y clausura del Monasterio ${ }^{23}$.

Las donaciones reales fueron cuantiosas durante siglos, siguiendo la tradición de su fundador Alfonso VII. Incluso en una de Alfonso XI se le recuerda como el primero que concedió «heredades» al monasterio. Todas ellas contribuyeron a incrementar su importante dominio, uno de los más importantes de la Orden en España, que se extendía por la región del Bajo Miño, atravesando la frontera portuguesa hasta Lisboa. Así los monarcas de Portugal concedieron al monasterio otros privilegios. Los autores de los tumbos, muy celosos de administrar la hacienda del cenobio, se ocuparon de registrar su contenido a lo largo de los siglos, a partir de los originales conservados en su archivo. Lo mismo hicieron con las bulas y los documentos privados (testamentos, foros, cartas de donación y de compra). De estos registros se conservan el llamado tumbo viejo (1627),

${ }^{19}$ GAITE, 1991, II, p. 34.

${ }^{20}$ TAMUXE, 1989, pp. 248-253.

${ }^{21}$ GAITE, 1991, II, p. 31.

${ }^{22}$ Biblioteca Penzol, Ms. 91.

${ }^{23}$ Tumbo pequeño, en AMEAL GONZÁLEZ, 1950, pp. 162-163. 
con interesantes anotaciones sobre el oficio de archivero y granjero, y la forma de hacer los foros ${ }^{24}$; el tumbo grande (ca. 1700), con dos abadologios y un amplio registro del dominio monástico ${ }^{25}$, y el tumbo pequeño (1739), más centrado en los orígenes y en la historia del cenobio ${ }^{26}$. El dominio monástico medieval ha sido analizado por varios autores a partir de los numerosos pergaminos conservados en el Archivo Histórico Nacional ${ }^{27}$.

Además de la sucesiva confirmación de privilegios reales por parte de los monarcas, cabe citar, entre los más interesantes para el desarrollo histórico del cenobio, la concesión del realengo de Saa y la iglesia de Erizana (11-IV-1201), eximiendo de tributo a los barcos del monasterio que llegasen al puerto de Erizana. A cambio de ello, el monasterio cedía el coto de Erizana para su repoblación. En 1228 reciben la isla de San Martín, una de las Cíes, con la obligación de celebrar en su ermita misas y honras fúnebres por el monarca, indicio de que el monasterio poseía embarcaciones, como también lo confirma el privilegio anterior ${ }^{28}$.

En relación con la flota del monasterio y la actividad pesquera para incrementar su mantenimiento, en 1286 Sancho IV les concedió veinte pescadores que habitasen cerca del cenobio. $\mathrm{Al}$ año siguiente, a petición del abad, que argumentaba que la costa de Oia era «escabrosa y brava» y los pescadores no podían mantenerse, se autorizó su traslado al coto de Malvas (Malves de Jusaos) para aprovechar el rendimiento de la pesca fluvial $^{29}$. En 1554 hay constancia en Malvas de unos «pescadores con siete pinazas, que pescaban para el monasterio de Oya $\aleph^{30}$.

Otra importante actividad desarrollada por los monjes cistercienses, y citada en el privilegio de Alfonso IX (Tui, 14-IV-1201), es la cría de caballos salvajes en los montes del monasterio de Oia, origen de los «curros», que todavía se celebran en Mougás y sus alrededores ${ }^{31}$.

\footnotetext{
${ }^{24}$ AHN, Clero, libro 10.181. .

${ }^{25}$ AHN, Códice 60 B.

${ }^{26}$ Banco Pastor, publicado por Ameal González.

${ }^{27}$ PALLARES MÉNDEZ y PORTELA SILVA, 1971, pp. 69-117; SÁNCHEZ CARRERA, 1997.

${ }^{28}$ PALLARES MÉNDEZ y PORTELA SILVA, 1971, pp. 95-96.

${ }^{29}$ Tumbo pequeño, en AMEAL GONZÁLEZ, 1954, p. 121.

${ }^{30}$ Ibidem.

${ }^{31}$ SÁ BRAVO, 1983, pp. 313-314.
}

«CUADERNOS DE ESTUDIOS GALLEGOS», Tomo XLIX, Fascículo 115, Santiago 2002. 
El Cisma de la Iglesia, con la escisión de las obediencias aviñonesa y romana, que abrazan los reinos de Castilla y Portugal, lo sufren los monjes de Oia en su propia casa, con la huída de su abad fray Gonzalo de Silva a la granja de Silva (Valença de Miño), que pertenecía al dominio del monasterio. El nuevo abad fray Rodrigo de Figueroa, temiendo represalias del reino vecino, porque su antecesor era cismático y apoyaba al monarca portugués, solicitó el apoyo real para que les tutelasen los oficiales de Baiona ${ }^{32}$.

Desde mediados del siglo $\mathrm{XV}$, los monasterios gallegos sufren una aguda crisis debido a la actuación de los abadades comendatarios, que se ausentaban de los monasterios y se preocupaban más de administrar las rentas que de la observancia religiosa. Además, la nobleza se había apoderado de buena parte de sus bienes. Los monasterios se hallaban en mal estado por falta de medios para acometer nuevas empresas o reparaciones. Ello trajo consigo la intervención de los Reyes Católicos y del papa Inocencio VIII. Su sucesor Alejandro VI encargó la reforma de los monasterios cistercienses gallegos a fray Martín de Vargas a través de la Congregación de Castilla. Acibeiro y Peñamaior se incorporaron de inmediato en 1505. Pero Oia opuso resistencia durante años, pese a las intervenciones de la Corte, siendo el último de los gallegos. El abad perpetuo fray Gregorio Nieto huyó de los reformistas a Portugal, con todo el pan y vino del monasterio y se encerró en la mencionada granja de Silva. Los monjes pasaron unos años muy difíciles hasta su incorporación a la observancia del Cister en octubre de 1547, por cesión del clérigo sevillano Alonso Morán, «que la tenía en encomienda» ${ }^{33}$. Todos los monasterios cistercienses se beneficiaron de la reforma y pudieron emprender importantes obras de reconstrucción y ampliación en sus cenobios ${ }^{34}$.

El emplazamiento del monasterio de Oia obligó a los monjes a desarrollar labores defensivas en su coto y monasterio. A la fortaleza y a la artillería del monasterio dedica un capítulo el tumbo de $1739^{35}$. Cabe suponer que desde los primeros años ya existiese una "tropa reglada». Así lo sugiere el documento de Alfonso XI (1337), que eximía a los vasallos

\footnotetext{
${ }^{32}$ GARCÍA ORO y PORTELA SILVA, 1995, p. 26.

${ }^{33}$ Tumbo pequeño, en AMEAL GONZÁLEZ, 1951, pp. 102-109, 218-221.

${ }^{34}$ YÁÑEZ NEIRA, 1974, pp. 168-175; GARCÍA ORO, 1991, pp. 663-664.

${ }^{35}$ En AMEAL GONZÁLEZ, 1954, pp. 216-220; SÁ BRAVO, 1972, pp. 316-318.
} 
de Oia de trabajar en la restauración del castillo de Tenca (Entienza), para que pudiesen atender a sus obligaciones defensivas en la costa que circundaba al monasterio. En 1351, Pedro I volvía a conceder la misma gracia a los vasallos del monasterio, que habían sido reclamados para trabajar en la reparación de otro castillo. Se desconoce, sin embargo, cuando se formó la compañía de soldados, a la que se ha relacionado con el primitivo castillo. Se componía de capitán, alférez, oficiales y los vecinos de la jurisdicción de Oia, que hacían guardia permanente en el arrabal, puerto de Brandariz, río de Oxos y en otros lugares cercanos vigilando el horizonte marítimo. La compañía de soldados del coto de Oia se documenta por primera vez en una Real Provisión de 1580, por la que se dispone que los vasallos del reino de Galicia estén abastecidos de armas. Las de la jurisdicción de Oia: 41 arcabuces y 136 picas vinieron de Vizcaya y Guipuzcoa, y el abad del monasterio se encargó de abonar su importe y de los gastos de su traslado. Desde entonces hay constancia documental, en varios inventarios del siglo XVII, de que las armas se depositaban en el monasterio y los vasallos las utilizaban para impedir el desembarco de corsarios. El abad, con rango de general, convocaba a los vecinos de la jurisdicción cuando se avecinaba el peligro en la costa.

La artillería, dispuesta en los muros de la plaza de Armas del monasterio, parece que se remonta al 1618 (Fig. 2). Ese año, el abad solicitó al capitán general del reino de Galicia dos piezas de batería para su defensa. Por orden Real se le entregaron algunas de la fortaleza de Baiona. Los propios monjes se encargaban de su reparación, mantenimiento y de la preparación de pólvora. En 1621 había siete piezas de artillería en la plaza de Armas, que el monarca había concedido al monasterio. En el llamado Libro de Unión se cuentan muchos detalles sobre el deseo de los monjes de eludir «el entretenimiento de la batería, pero siempre se insistió por la Corte que era obligación del monasterio» ${ }^{36}$. Los cistercienses de Oia protagonizaron muchos acontecimientos históricos, defendiendo la cala y disparando las piezas de artillería que se alzaban sobre la cerca monacal. El 14 de marzo de 1624 lucharon contra unos corsarios turcos que atacaban a dos barcos, uno francés y otro inglés. El 20 de abril del mismo año ayudaron a dos naves portuguesas y una francesa, que intentaban

\footnotetext{
${ }^{36}$ Tumbo pequeño, en AMEAL GONZÁLEZ, 1952, p. 219.
} 
desembarcar en la cala del monasterio cuando eran perseguidas por cinco naves turcas. Ambos sucesos están muy documentados, y por su valerosa actuación se les conoció desde entonces como los monjes artilleros. Para su defensa contaban con siete piezas de artillería, once mosquetes, balas y pólvora, que se mencionan en el inventario de 18 de julio de $1623^{37}$. El rey Felipe IV le concedió a su templo el título de Santa María la Real de Oia y le confirmó el de Imperial y Real monasterio que ya disfrutaba ${ }^{38}$.

En el siglo XVIII, los monjes continuaron realizando las mismas tareas. El abad fray Carlos Suárez (1741-1744) reforzó la defensa en la plaza de Armas, comprando cuatro cañones con sus cureñas y ordenó la limpieza de las tres que ya había. En 1761, la batería se incrementó con otros dos cañones, los mayores que tuvo el monasterio, que fueron regalados por el capitán de un barco inglés, al que se había dado asilo en el monasterio. Otros abades se encargaron de su mantenimiento; así fray Bernardo Sánchez (1787-1791) compuso las cureñas de los mismos cañones.

Durante el abadologio de fray Joaquín Macías (1807-1812), el monasterio sufrió los daños de la invasión francesa, aunque se desconoce el alcance de los mismos. Los monjes fueron expulsados de los monasterios. Sus sucesores se ocuparon de la restauración de los edificios.

En el período constitucional, con la nueva expulsión de los monjes entre 1820-1823, el edificio del monasterio fue desmantelado y sufrió daños considerables. Algunas obras de restauración fueron acometidas por el abad fray Felipe Fernández (1824-1828).

La exclaustración y la desamortización (1835) obligaron a los monjes de Oia a abandonar el monasterio y desde entonces se fueron dispersando sus bienes. En 1838, la iglesia, bajo el título de Santa María de Oia, se constituyó en parroquial. Hasta esta fecha la villa de Oia había pertenecido a la feligresía de San Mamede de Pedornes. El monasterio y sus propiedades pasaron a subasta. El remate del edificio se llevó a cabo el 15 de abril de 1844 en las Casas Consistoriales de Pontevedra. «Por hallarse sumamente deteriorado y en estado de ruina, sin servicio para fábrica, por falta de agua, ni ventajosa demolición, por hallarse a bastante distancia de poblaciones, lo regularon los peritos en 16.600 reales». En principio

\footnotetext{
${ }^{37}$ AHN, Libro 10.220 .

${ }^{38}$ SÁ BRAVO, 1972, pp. 316-318.
}

«CUADERNOS DE ESTUDIOS GALLEGOS», Tomo XLIX, Fascículo 115, Santiago 2002. 


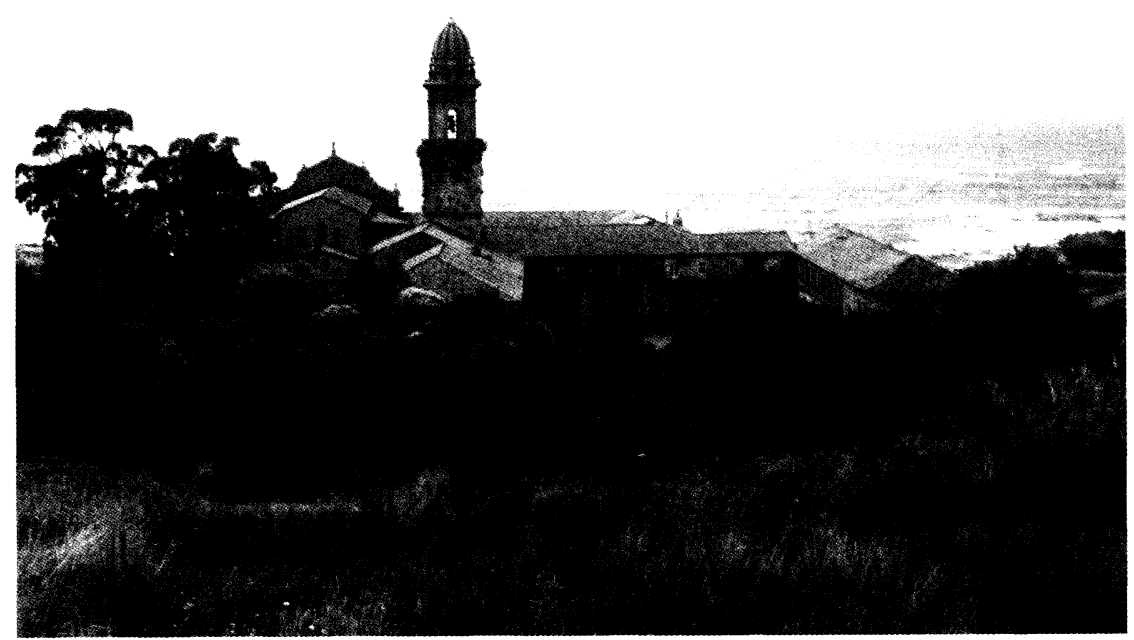

Fig. 1. Vista general del monasterio.

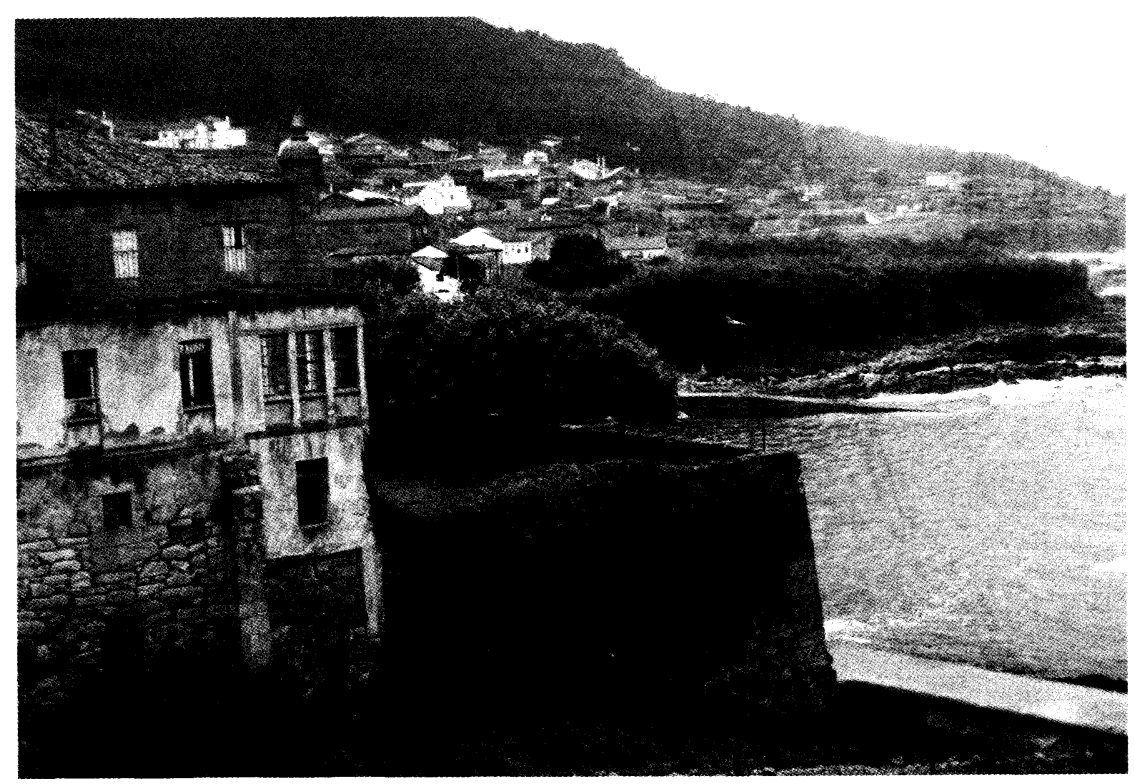

Fig. 2. Conjunto del costado noroeste.

«CUADERNOS DE ESTUDIOS GALLEGOS», Tomo XLIX, Fascículo 115, Santiago 2002. 


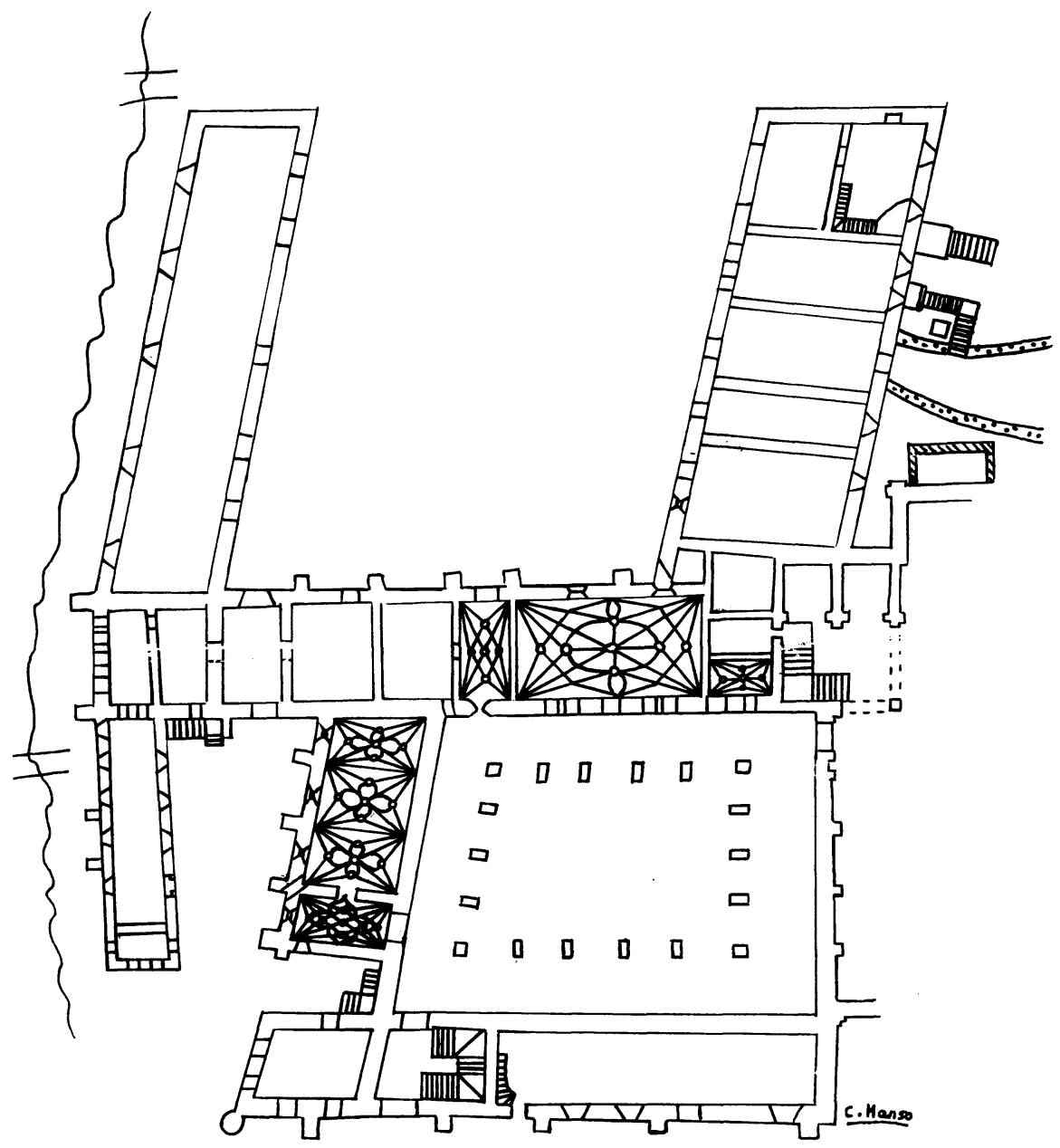

Fig. 3a. Croquis del monasterio (según Carmen Manso).

«CUADERNOS DE ESTUDIOS GALLEGO``», Tomo XLIX, Fascículo 115, Santiago 2002. 


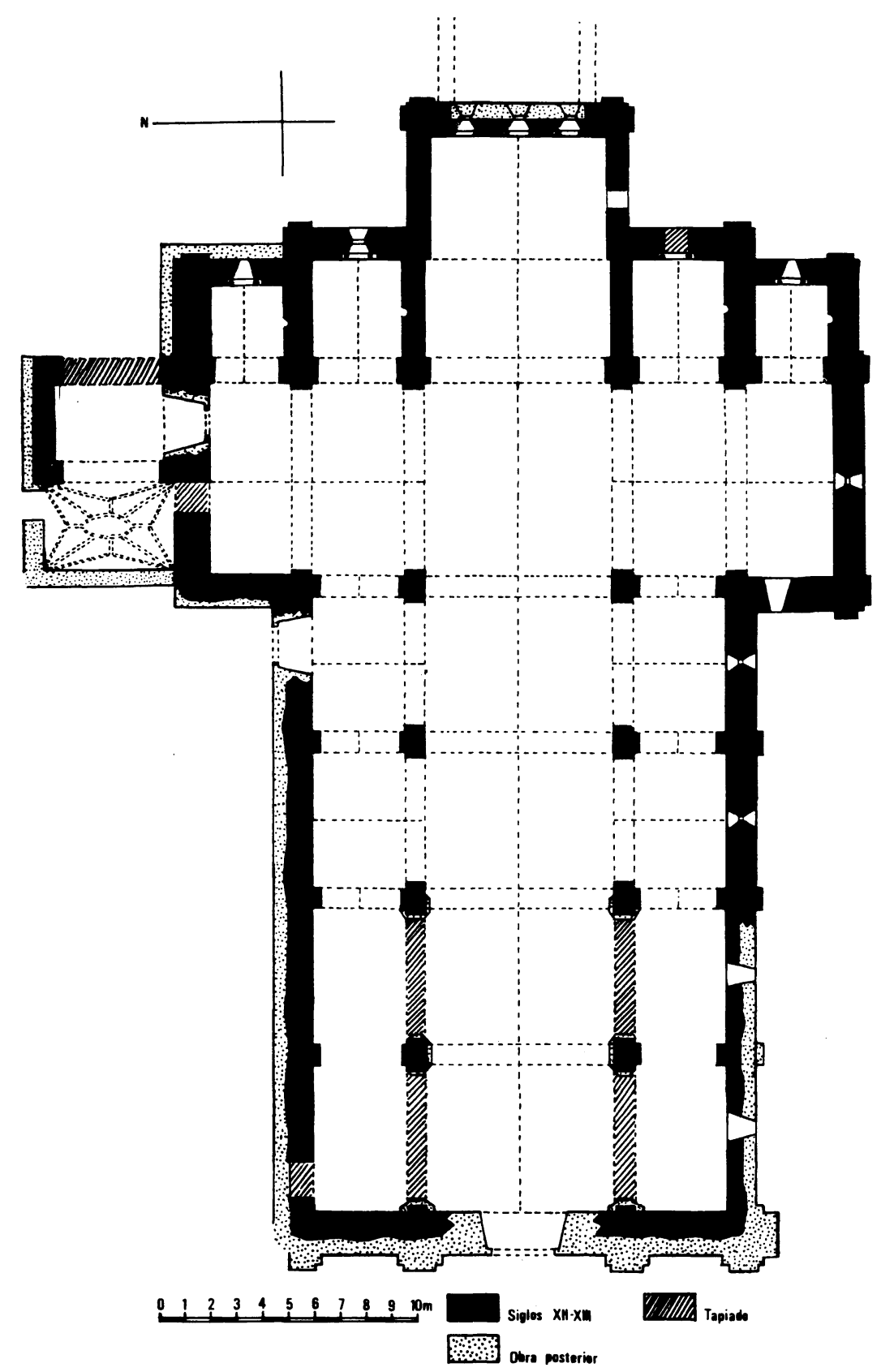

Fig. 3b. Planta de la iglesia (en Valle Pérez, 1982, fig. 10, p. 277).

«CUADERNOS DE ESTUDIOS GALLEGOS», Tomo XLIX, Fascículo 115, Santiago 2002. 
se decidió arrendar por dos años a Lorenzo de Cuenca, pero se presentó otro candidato: José María López, representando a Fernando Fernández Casariego, vecino de Madrid, que ofreció 200.000 reales para pagar al contado en papel de deuda ${ }^{39}$. Poco después, Fernando Fernández Casariego lo vendió a Joaquín Alonso, natural de A Guardia, que rehusó a su marquesado y mayorazgo. Éste tuvo problemas con los antiguos foreros, que se negaron a pagar su importe y provocaron un incendio en el monasterio, que pudo ser atajado a tiempo. En 1912, el pleito del foro salió a favor del propietario, pero como los vecinos se negaron nuevamente a pagar, los foros quedaron abolidos ${ }^{40}$. En una fotografía de hacia 1910 se puede ver el lamentable estado del monasterio, quizá después del incendio, pues falta toda la cubierta del edificio que da a la plaza de Armas ${ }^{41}$. Ese año se alquiló a los jesuitas portugueses. Allí establecieron un prestigioso colegio y realizaron diversas obras para acondicionar el edificio. Emplearon la capillita que había construido su propietario en el costado oriental que da al patio de los Naranjos. En la portada se conservan las siglas -IHS- de la Orden. Durante la República, los jesuitas tuvieron que abandonar España (1932). El Estado incautó el monasterio, pensando que era propiedad de la Compañía. El alcalde de Oia quedó al cargo de su administración. El monumento sufrió entonces daños considerables. Al parecer los vecinos se llevaron muchas piezas y materiales de su alzado para la construcción de algunas casas del pueblo: «sillares, puertas, ventanas, vigas y herrajes» ${ }^{42}$. Los años de la guerra civil continuaron siendo infructuosos para la conservación del monasterio. De su empleo como prisión quedan algunos testimonios escritos de presos catalanes, en los muros de la mencionada capilla de la Compañía en el costado oriental, que da al Patio de los Naranjos.

Superada esta durísima etapa, el monasterio comienza otra más beneficiosa para la recuperación de su conjunto. Por herencia de los descendientes de Joaquín Alonso, la propiedad pasó a manos del sacerdote Javier Bouso Arias, que realizó valiosas obras para su recuperación, según

\footnotetext{
${ }^{39}$ Archivo Histórico Provincial de Pontevedra, G 8071. Agradezco esta información a Antonio Taboada Táboas.

${ }^{40}$ SÁ BRAVO, 1972, pp. 318-319.

${ }^{41}$ YÁÑEZ NEIRA, 1974, p. 144, lám. XVIII.

${ }^{4}$ SÁ BRAVO, 1972, pp. 318-319.
} 
cuenta, en 1949, el P. Manuel Ameal González, de la Orden del Císter, en la introducción que hace al tumbo pequeño (1739). Este manuscrito, adquirido por los actuales propietarios, le fue prestado por el citado sacerdote para elaborar su trabajo ${ }^{43}$. Al parecer a Javier Bouso «se debe la restauración de la antigua portada abacial, en parte; el hermoseamiento de dependencias interiores; el retejado de sus largas techumbres, que manos enemigas incendiaran en distintas épocas; la limpieza de tránsitos y salas que, durante la pasada guerra, sirvieron momentáneamente de prisión; el adecentamiento de salas, que todo ello da el aspecto de una sana renovación total, presagio de ulteriores y necesarios designios $\rangle^{44}$. Por entonces, la Orden del Císter había contactado con el sacerdote para establecer en el monasterio una comunidad de monjas cistercienses, pero no se llegó a ningún acuerdo. Su hermano Daniel Bouso y su esposa recibieron en herencia la parte llamada «El Bosque», situada al otro lado de la carretera general, que hoy pertenece a sus descendientes. En una de las habitaciones del tercer piso que da al Patio de Oficinas, entrando por la escalera principal, se conserva un vaciado de yeso con el diseño de la «finca El Bosque», firmado por Antonio Crespo en Tui (1918). El resto de la propiedad del monasterio fue adquirida por José García, el penúltimo propietario, que habitó las habitaciones de la Huerta y del patio de Armas. En estas últimas, al parecer organizó un Museo de animales disecados. Sus hijos lo vendieron a la familia Masaveu. A finales de 1999 fue adquirido por el Grupo Banco Pastor. Un ambicioso proyecto de restauración y rehabilitación del edificio permitirá su recuperación total. Su nuevo destino como Gran Hotel augura el comienzo de una nueva etapa brillante y explendorosa en los primeros años del siglo XXI.

\section{ANÁLISIS HISTÓRICO-ARTÍSTICO: ESTILOS Y ETAPAS CONSTRUCTIVAS}

La iglesia presenta planta de cruz latina de tres naves, de doble anchura la central. En el perímetro del transepto se abren cinco capillas

\footnotetext{
${ }^{43}$ Revista Cistercium, 1949-1956.

${ }^{44}$ AMEAL GONZÁLEZ, 1949, p. 116.
}

«CUADERNOS DE ESTUDIOS GALLEGOS», Tomo XLIX, Fascículo 115, Santiago 2002. 
rectangulares y escalonadas en sus cabeceras a partir de la mayor, ésta de doble profundidad. Se inspira en la llamada "planta bernarda», la más pura de las cistercienses. Pero el escalonamiento de sus capillas menores difiere de su prototipo -que cierran en un mismo muro recto a oriente- al igual que el empleo de dos ábsides por brazo. Este rasgo es singular dentro del panorama europeo, pues constituye el único ejemplo conservado y probablemente se haya inspirado en un modelo borgoñón (Fig. 3b).

El alzado del interior, de los más austeros y sencillos, es el que mejor responde a los ideales de la primera arquitectura cisterciense. Pilares y pilastras, de sección rectangular, soportan las bóvedas de cañón apuntadas en la cabecera, tramo del crucero y nave central en sentido longitudinal a su eje, y las mismas, pero en disposición perpendicular, en los tramos de las naves laterales y brazos del transepto. Los arcos fajones de la nave central apean en ménsulas escalonadas. Los demás lo hacen sobre sencillas pilastras impostadas. Ventanas con arco de medio punto y rosetones iluminan el interior. Algunos han sido tapiados o eliminados, al practicarse algunas reformas en el testero de la capilla mayor -adición de una sacristía en el siglo XVIII- y al renovarse la fachada a principios del siglo XVIII. Los dos últimos tramos también fueron reformados, cuando se levantó el coro alto en el último tercio del siglo XVI. Otras alteraciones sufrió el testero norte del transepto en los vanos de acceso a la sacristía y a la torre durante los mencionados siglos.

La fábrica medieval sigue en su conjunto el modelo supervisado por San Bernardo en Clairvaux II (1135-1145). Las obras, iniciadas hacia 1190, debieron de concluir hacia el 1230. Datos legendarios, tomados de una historia manuscrita de Oia, vinculan la fábrica a un maestro foráneo llamado Bernardo, que dirigió un equipo de canteros familiarizados con las fórmulas de la mencionada abacial borgoñona. En opinión de Valle Pérez, el relato tendría un fondo de verdad, en el sentido de desplazarse los maestros de la Orden de la casa madre de Clairvaux, para dar las trazas de las fundaciones de su misma filiación. Así se explica el impactante «exotismo de su planta y alzado», que luego se difunde en la iglesia colegiata de Baiona, en cuya fachada (1278), de aspecto defensivo, tenemos una muestra de lo que pudo ser la de la abacial de Oia. De la misma manera que en la maqueta que porta San Bernardo en una pintura del retablo de la capilla mayor (ca. 1600), salvando algunas pe- 
queñas diferencias en su diseño, se ha identificado «su configuración inicial» ${ }^{45}$.

\section{El Monasterio}

Las dependencias del monasterio se abren en el costado sur de la iglesia. A partir de la incorporación de Santa María de Oia a la Congregación de Castilla de la Orden Cisterciense (1547) se inició una fructífera actividad constructiva, que trajo consigo la renovación total de la fábrica medieval de su monasterio. No menos destacable fue la ampliación y reedificación de importantes estancias durante los siglos XVII y XVIII, de las que permanecen buenos testimonios en las galerías que se abren a ambos costados del patio de los Naranjos y en la torre, entre las más significativas, y que apenas han sido estudiadas. El descubrimiento de este precioso monumento renacentista y barroco, dentro de una línea de clasicismo sereno, y el trabajo de campo realizado en su interior ha sido una experiencia muy grata. Cabe lamentar el estado de las cubiertas, excepto la del segundo piso del claustro, restaurada recientemente, y el de los pavimentos de madera. En algunas zonas, los muros se hallan dañados por la humedad, las materias orgánicas y la erosión. Gracias a los testimonios documentales y epigráficos, algunos inéditos, y al conjunto conservado, se puede escribir la historia constructiva del monasterio cisterciense, que sólo había sido analizada en el conjunto de la arquitectura monacal renacentista y barroca (Fig. 3a).

La fábrica medieval de las dependencias monásticas fue prácticamente renovada a partir de mediados y del último tercio del siglo XVI. Sin embargo se mantienen algunas estancias que comunicaban con la iglesia, como la sacristía y otra contigua a ella, y algunos elementos en la parte inferior e intermedia de la actual torre barroca; aunque todas ellas sufrieron algunas alteraciones en época moderna. Permanece también parte del alzado de una edificación que enlaza con la muralla en el costado norte (Figs. 2, 3a, 6).

Con el cenobio medieval cabría vincular a algunos maestros de obra, que figuran en pergaminos como otorgantes o testigos entre 1246 y 1290;

${ }^{45}$ VALLE PÉREZ, 1982, pp. 285-288; 1998, pp. 27-28.

«CUADERNOS DE ESTUDIOS GALLEGOS», Tomo XLIX, Fascículo 115, Santiago 2002. 
el último, Juan Pérez se llama «maestre da obra do moesteyro doya» ${ }^{46}$. Es posible que las obras estuviesen muy avanzadas hacia mediados del siglo XIII. Para Valle Pérez su claustro podría responder al mismo prototipo del conservado en la catedral de $\mathrm{Tui}^{47}$. Luego se irían levantando las demás habitaciones del cenobio.

Del conjunto de esta fábrica medieval fueron reutilizados muchos sillares y algunos lienzos de su alzado en la nueva campaña renacentista. Así, los signos lapidarios o marcas de cantero labradas en varios sillares del segundo piso del claustro de las Procesiones, en el muro oeste que comunica con las celdas; en el interior de éstas hay también algunos sillares medievales con los mismos signos. En los lienzos murales del espacioso tramo donde se alza la escalera barroca permanecen muchas huellas de la fábrica medieval. En el costado oriental que comunica con la puerta de entrada al claustro bajo y en su frontera sur, que da acceso a la planta intermedia de celdas, se localizan muchos signos lapidarios, algunos muy repetidos. En este último lienzo hay además marcas rehundidas -rectangulares y cuadradas-, en sendas hiladas de sillares, que sugieren la existencia de una posible cubierta en esta zona, aunque en el lienzo frontero no se perciben las mismas huellas. Los muros están muy retocados y en algunas partes se ha reemplazado la sillería, de buen aparejo, por mampostería. Precisamente sobre la portada de acceso al claustro bajo hay claros indicios del dovelaje de un arco ojival, de sección prismática, a la altura de la cubierta abovedada de la galería del claustro, y que podría pertenecer a la bóveda de aquella estancia (Figs. 4-5).

En el lienzo norte, que comunica el claustro procesional con el patio de los Naranjos, al parecer se localiza un sillar con roseta inscrita en un círculo, del segundo y tercer cuarto del siglo XIII, con paralelos en la colegiata de Baiona ${ }^{48}$. Otras muchas marcas de cantero sin duda aparecerán cuando se limpien las capas de cal y cemento, y la vegetación que cubren algunas partes del edificio.

En el Museo formado por los anteriores propietarios se conservaba un capitel vegetal del siglo XIII, reutilizado como pila ${ }^{49}$. Actualmente se ha-

\footnotetext{
${ }^{46}$ FERNÁNDEZ RODRÍGUEZ, 1956, pp. 226-228.

${ }^{47}$ VALLE PÉREZ, 1982, pp. 288-289.

${ }^{48}$ Ibídem, pp. 289-290.

${ }^{49}$ Ibídem, p. 289.
} 
lla en paradero desconocido y es de esperar que aparezca al limpiar las habitaciones inferiores que comunican con el Patio de los Naranjos, donde se almacenan muchas piezas sueltas de granito: sillares labrados con molduras, fragmentos de una fuente barroca, etc.

En el interior de la iglesia se perciben vanos tapiados que daban acceso al monasterio medieval. Así, la puerta de los conversos en el último tramo de la nave norte, de sencillo arco de medio punto; la puerta de maitines en el transepto norte, que daba acceso al dormitorio común de los monjes, de arco ojival, y la ventana tapiada del mismo transepto que iluminaba la iglesia desde las dependencias monacales.

A la sacristía medieval se accede desde el mismo lugar, por medio de una portada adintelada del siglo XVIII, que reemplaza a la primitiva. Se conserva sólo el tramo occidental con bóveda de cañón. Para Valle Pérez el segundo tramo se prolongaría hacia el este en línea con el testero de las capillas, ocupando el actual espacio de la torre barroca. Junto al tramo de sacristía conservado se halla otra estancia en comunicación con ella, algo más alta, que el mencionado autor identifica con el lugar donde se situaba la escalera de subida al dormitorio medieval, y en su lienzo sur se abría la puerta de maitines ${ }^{50}$. La actual bóveda de crucería con terceletes y cinco claves con rostetas, en mi opinión es anterior a la campaña del último tercio del XVI, que ahora veremos, y cabe situarla hacia finales del siglo XV o principios del siglo XVI (Fig. 3a).

En el segundo piso del costado oriental, encima de la sacristía y en el tramo de subida de la torre, se conservan dos arcos ojivales y huellas de arcos tapiados. Lo más probable es que en este lugar se localizase el dormitorio medieval.

De la fábrica medieval también permanece parte del alzado inferior de un edificio de planta rectangular, hoy compartimentado en varias estancias y muy arruinado, que comunica con el patio de Oficinas por el lado sur y con el regato, foso y Prado por el lado norte. En su extremo oriental enlaza con la nueva galería norte del patio de los Naranjos levantada durante el primer cuarto del siglo XVIII. En su extremo occidental comunica con la plaza de Armas y sus muros forman parte de la muralla del monasterio. Por el costado sur se une a la línea de habitaciones que se

\footnotetext{
${ }^{50}$ Ibidem, p. 289.
} 
abren al patio de Oficinas y al claustro Procesional. Los cuatro contrafuertes prismáticos con remate escalonado, que refuerzan los muros del costado norte, responden a la misma tipología empleada en el templo medieval. El aparejo de estos estribos es de buena sillería, a diferencia del de mampostería empleado en los lienzos murales. En estos se practicaron vanos rectangulares modernos, que acusan retoques más recientes de ladrillo. Hacia el primer tercio del siglo XX se añadió el último cuerpo de ladrillo y cemento, con una capa de cal y numerosos ventanales; hoy está arruinado (Fig. 12). Es muy difícil evaluar el sótano de esta construcción, debido a la vegetación que le cubre hasta el nivel del jardín. Tampoco se puede practicar su acceso desde el regato y foso, debido a la misma circunstancia. Una frondosa higuera ha cubierto el primitivo paso de entrada al recinto monasterial, a través de un puente con arco de medio punto, que termina en el muro del edificio junto a uno de los contrafuertes. Cabe pensar que éste fuese uno de los accesos al monasterio, quizás el empleado por la compañía defensiva. Aquí podría emplazarse el cuerpo de guardia, el depósito para el armamento e incluso también la enfermería de la compañía. La limpieza de esta zona sin duda facilitará un análisis más detallado del edificio. Lo que sí parece probable es que estuvo aislado de la estancia contigua por el costado sur y de la galería del Naranjal por el costado este. La primera se levantaría al terminar la campaña documentada en el último cuarto del siglo XVI y la segunda al iniciarse la galería norte del Naranjal en el siglo XVIII (Fig. 5). Esta hipótesis en mi opinión, explicaría el cambio de aparejo tan acusado que se aprecia, desde sus cimientos, en el lienzo mural del costado occidental de la galería, separado por una línea vertical, que sería la de la esquina del alzado. El costado correspondiente a la estancia primitiva ofrece obra de mampostería y la estancia supuestamente adosada, sillería de buena calidad. La línea llega hasta el segundo piso, lo cual sugiere que al menos este tramo medieval alcanzase esta altura, el doble que la contigua del oriente. A partir del remate de sus contrafuertes, el segundo piso se cubriría con armadura de madera. Sus esquinas han sido reforzadas con sillares de la obra del XVIII y sus vanos rectangulares responden a la misma tipología.

\section{El siglo XVI}

Desde el punto de vista artístico, la reforma de los monasterios gallegos fue muy beneficiosa, en la medida en que se restauraron las depen- 


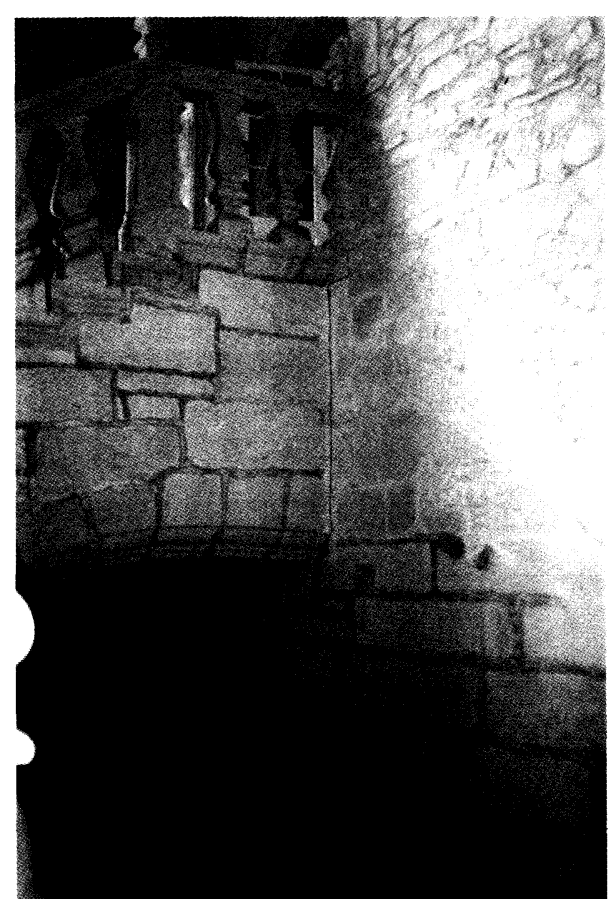

Fig. 4. Puerta de entrada al claustro bajo y escalera de acceso a las celdas y galería superior.

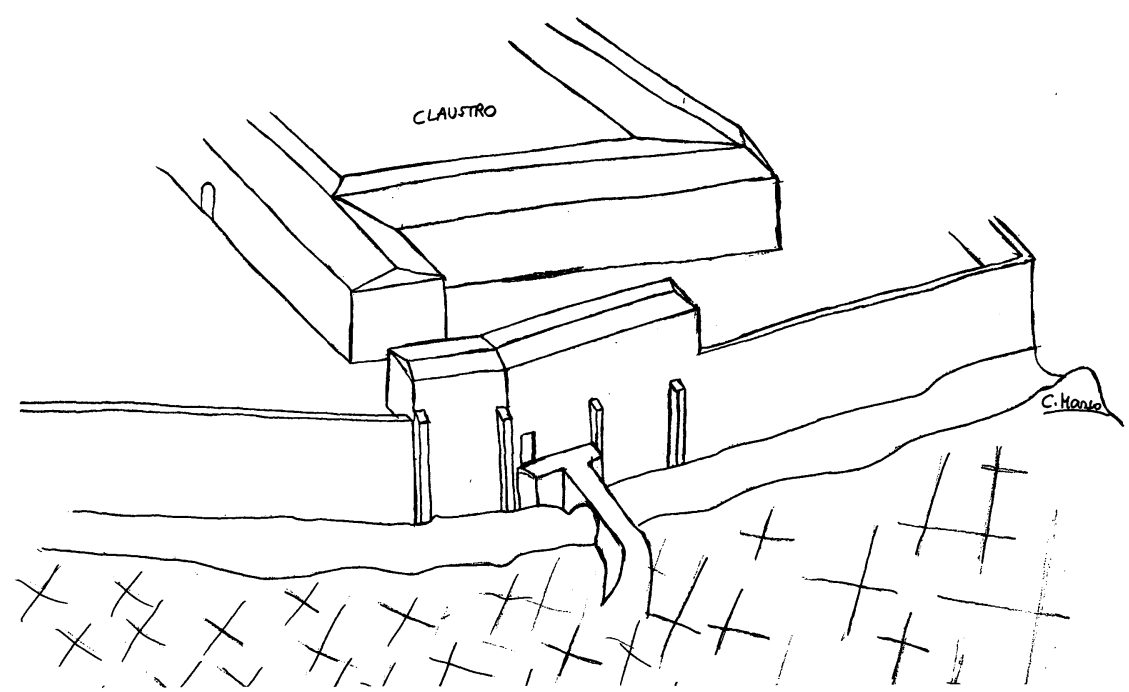

Fig. 5. Reconstrucción conjetural y parcial del alzado. Siglo XVI.

«CUADERNOS DE ESTUDIOS GALLEGOS», Tomo XLIX, Fascículo 115, Santiago 2002. 


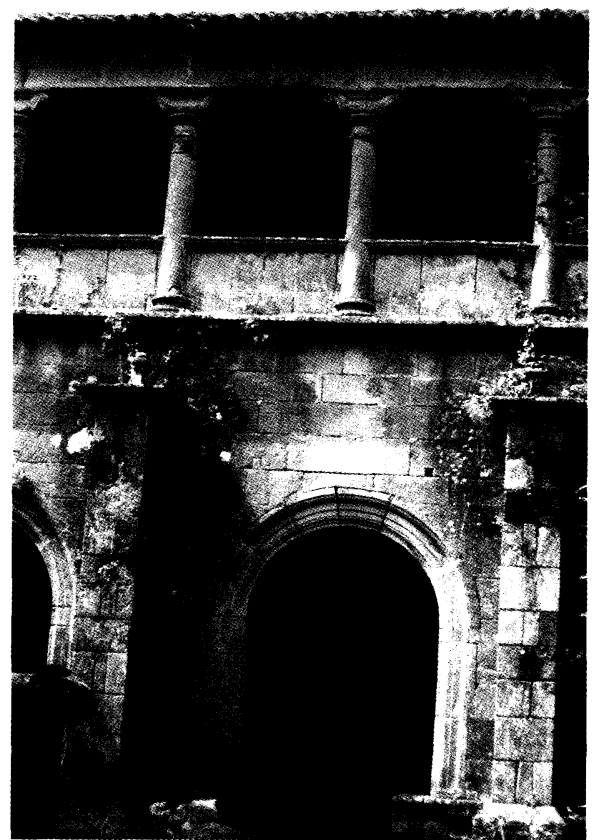

Fig. 6. Alzado de las galerías del claustro. Siglo XVI.

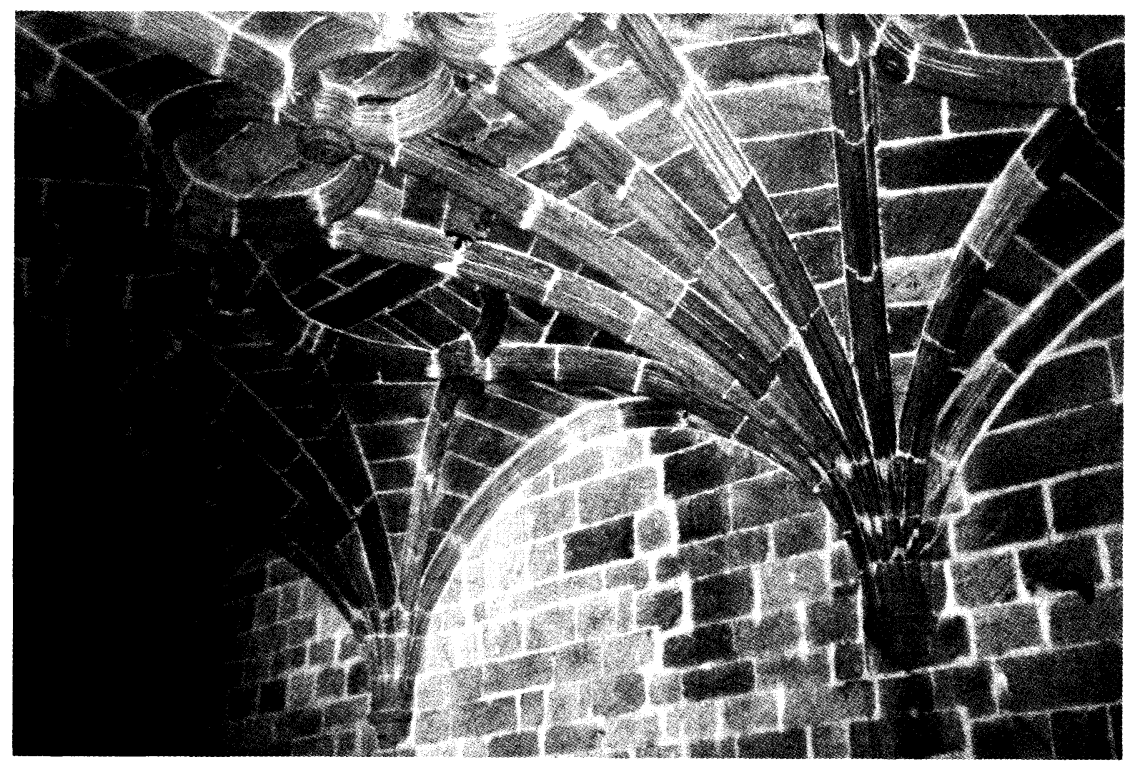

Fig. 7. Bóvedas del refectorio. Siglo XVI.

«CUADERNOS DE ESTUDIOS GALLEGOS», Tomo XLIX, Fascículo 115, Santiago 2002. 


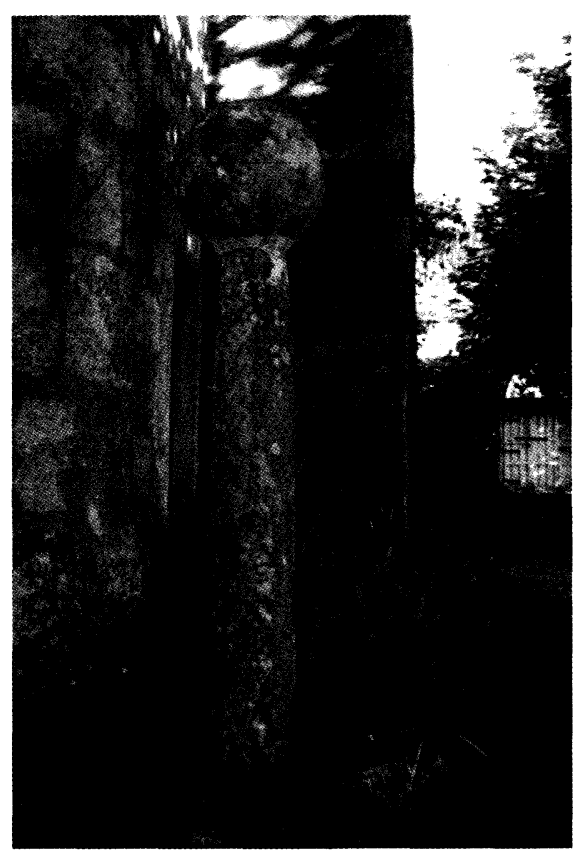

Fig. 8. Picota en la plaza de Armas junto a la torrecilla cilíndrica (rollo).

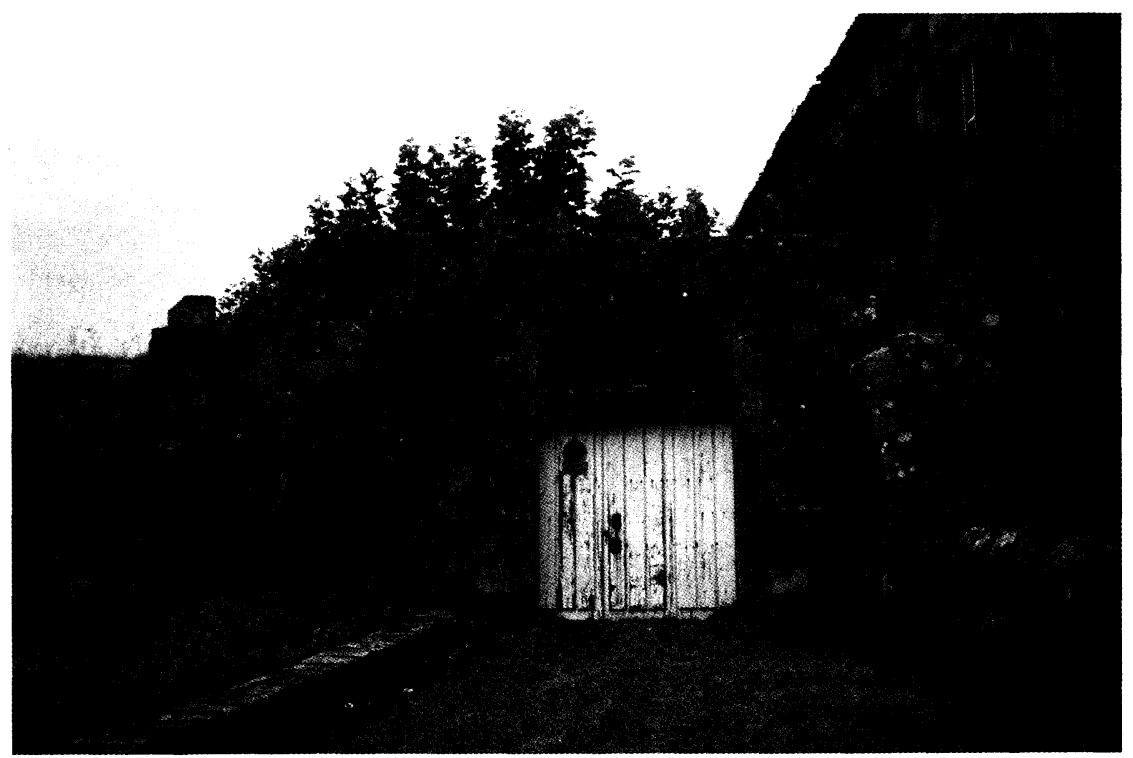

Fig. 9. Portada de acceso al monasterio por la plaza de Armas.

«CUADERNOS DE ESTUDIOS GALLEGOS», Tomo XLIX, Fascículo 115, Santiago 2002. 


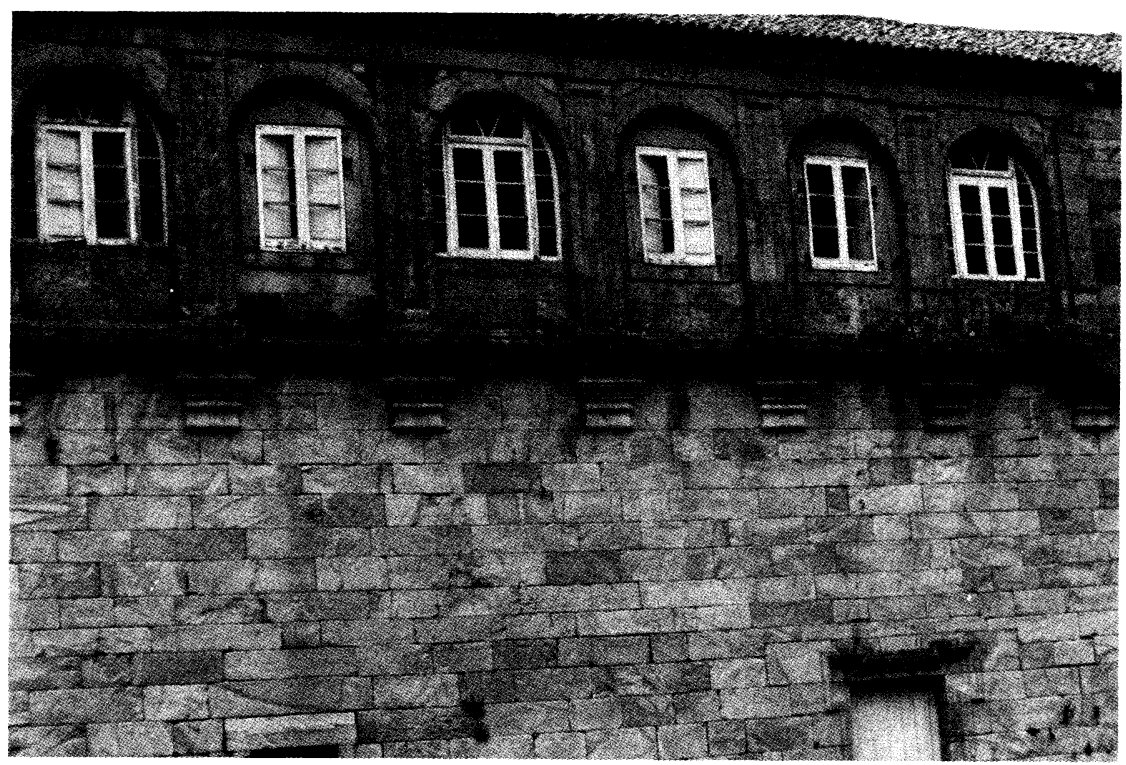

Fig. 10. Galería norte abierta al patio de los Naranjos. Epígrafe: «Año de 1739».

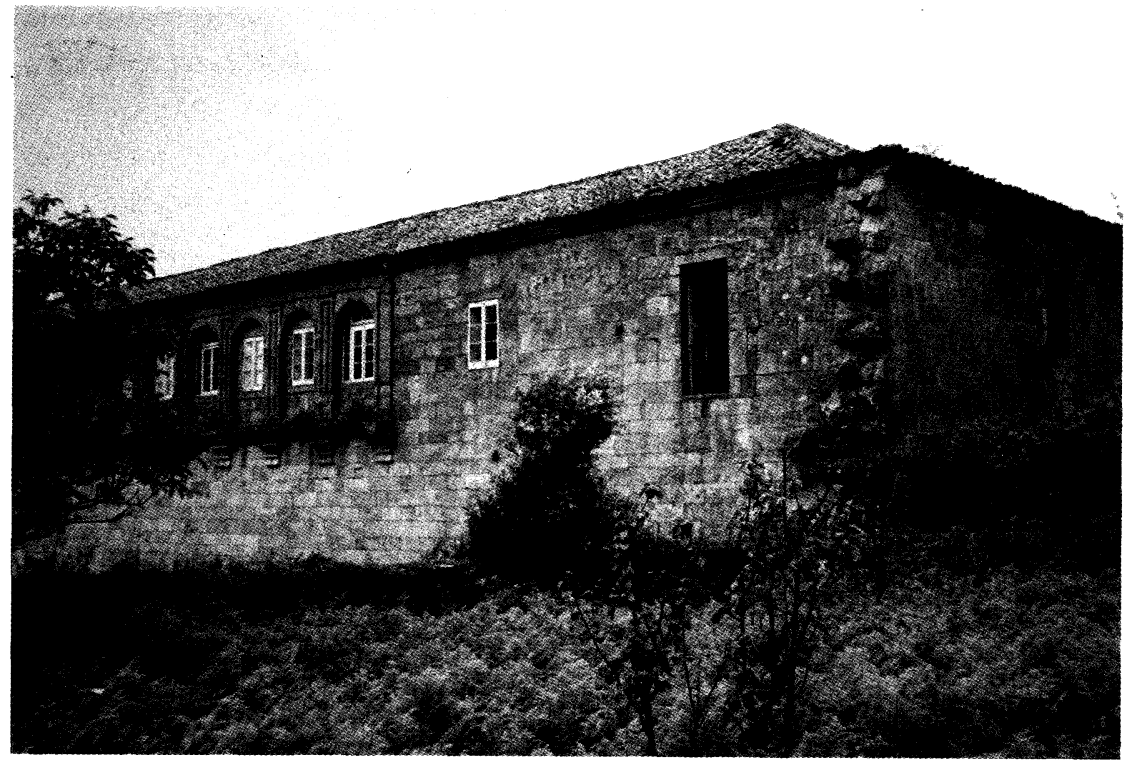

Fig. 11. Galería norte abierta al patio de los Naranjos. Remate oriental.

«CUADERNOS DE ESTUDIOS GALLEGOS», Tomo XLIX, Fascículo 115, Santiago 2002. 
dencias arruinadas y sobre todo se transformó la configuración de sus estancias para adecuarlas a la nueva vida monástica. Se incrementa el número de religiosos y el dormitorio común se transforma en celdas independientes. La vida monástica se desarrolla en torno al claustro Reglar o de las Procesiones, en dos pisos, y a él se abren las principales habitaciones del cenobio: sacristía, sala capitular, biblioteca, refectorio, cocina, celdas, auditorio, etc. Un segundo claustro, el de la Hospedería se destina a los peregrinos y en él se desarrolla la actividad administrativa y agrícola del monasterio. En algunos se levantó otro claustro mayor, al que se abrían las celdas de los monjes.

Como ya señaló Vila Jato, a lo largo del siglo XVI y la primera mitad del XVII en estos monasterios cistercienses trabajan activamente varios talleres de aparejadores, maestros de obras y canteros, que interpretan las trazas de un arquitecto relevante y difunden su estilo por Galicia, empleando fórmulas muy parecidas. Su estilo deriva del arte salmantino y de la obra de Rodrigo Gil de Hontañón. Un taller localizado en Ourense y Santiago bajo la dirección de Juan de Herrera de Grajano difunde el estilo en los monasterios cistercienses de Sobrado y Monfero. Un segundo taller desarrolla su actividad hasta principios del XVII, bajo la dirección del arquitecto Juan de Cerecedo el Viejo, que trabaja en Montederramo, San Clodio, Meira y Oia. Se cita en un documento de su viuda (1570), dado a conocer por García Cuetos, en el que reclama el pago de la obra que Cerecedo había emprendido en estos cenobios. En otro de 1571 se indica el traspaso de las obras a los maestros designados por los abades. A Pedro del Campo, vecino de Baiona, que fue aparejador del citado arquitecto, se le cedió la de $\mathrm{Oia}^{51}$. En su testamento (Santiago, 9-II-1581) tenemos noticia de su intervención. En efecto había rematado «la obra de los cuartos de los claustros», por un importe de 150 ducados, del que había recibido una cantidad. Además ya estaba contratada la obra del refectorio, conforme a una traza «de bóveda con sus ventanas» (Fig. 7). De ella había ejecutado hasta los «jarjamentos» y para terminarla tenía mucha piedra labrada, pero el abad le despidió con sus oficiales. Al parecer no pudo terminar la obra principal porque el abad le había encomendado otra, que desconocemos ${ }^{52}$. Es

\footnotetext{
${ }^{51}$ VILA JATO, 1993, pp. 187-199, 189-193.

52 PÉREZ COSTANTI, 1930, pp. 81-83.
} 
posible que interviniese en la construcción del pozo y canalización de las aguas, que vendrían de la parte alta del bosque, quizá del depósito que allí se conserva. Varias piezas de sillería sueltas - «caños de piedra» rectangulares- conservadas en el claustro bajo pertenecen a esta canalización. De la experiencia de Pedro del Campo en esta empresa hay noticia en la obra del pozo de Monterreal en Baiona (1579-1580) de bella factura arquitectónica, con escaleras y $\operatorname{arcos}^{53}$. A otro maestro, Bartolomé de Hermosa, que también trabajó con Cerecedo, se le viene atribuyendo el remate de la fábrica del monasterio y las bóvedas del coro alto a los pies del templo.

La campaña renacentista se inicia en el claustro Procesional, que se alza junto a la nave norte del templo, con cuatro arquerías en este costado $\mathrm{y}$ en el frontero, y cinco en el oriental y occidental, asentadas sobre un poyo corrido. Las galerías se cubren con bóvedas de crucería, con terceletes y ligaduras, que voltean en ménsulas gallonadas; los nervios organizan un rombo central, que cobija la clave mayor con florón; las demás claves salientes se ornan con rosetas y molduras de elegante diseño. Este sistema se inspira en el claustro renacentista de la catedral de Santiago y es similar al de otros claustros cistercienses levantados por los talleres de Herrera de Grajano. Los robustos contrafuertes del patio central, que soportan los empujes de las bóvedas, rematan en el arranque del piso superior en imposta saliente con pequeños pináculos. Sobre la cornisa del primer cuerpo se alza un muro corrido, a modo de mirador, que se une a la parte inferior del fuste de una galería adintelada. Las columnas, dos por cada tramo del cuerpo inferior, de fuste liso y capitel dórico, soportan bellas zapatas, con variados motivos ornamentales, sobre las que apean un friso casetonado y la cornisa. Algunas zapatas, al igual que los fustes, acusan daños de erosión (Fig. 6). Su organización es similar a las de otros claustros levantados por los talleres de Herrera de Grajano (San Clodio, Ribas de Sil, etc.). Como ya señalaron Bonet $\mathrm{Correa}^{54}$ y Vila Jato ${ }^{55}$, las columnas con zapatas, de origen castellano, fueron introducidas en Galicia por Gil de Hontañón. Se inspiran en las de la galería occidental del claustro de la catedral de Santiago, que sigue la traza del mencionado arquitecto.

\footnotetext{
${ }^{53}$ GARCÍA ORO y PORTELA SILVA, 1995, pp. 52-53.

${ }^{54}$ BONET CORREA, 1966, p. 63.

${ }^{55}$ VILA JATO, 1993, p. 192.
} 
El costado norte de la galería superior ofrece una organización diferente: ha sido cerrada y compartimentada con pilastras toscanas de fuste cajeado, cuatro vanos -dos rectangulares y dos lobulados-, y un balcón central con puerta de arco carpanel. Quizá forme parte de la misma campaña, pues bajo la plataforma volada del balcón, el remate de los contrafuertes ofrece un perfil cóncavo, y los mismos pináculos, para adecuarse al ritmo de líneas cóncavas de aquella. Seguramente se ha querido levantar una fachada más noble, contigua a la sala y celda abacial. La galería se cubre con artesonado liso -restaurado recientemente- y se mantienen las zapatas de madera, con molduras y remates en voluta, que la sujetan. La cubierta de los cuatro lienzos fue rehecha por el abad José de Moedes (1733-1738). Además de levantarla, enmaderarla y tejarla, «hizo guardapolvos para resguardo de las medias naranjas» en las esquinas ${ }^{56}$.

El acceso al claustro bajo desde el patio de Armas se realiza desde el costado noroccidental, por medio de una puerta de arco de medio punto moldurado, muy similar a los arcos de las galerías (Fig. 4). Otra bella portada monumental de estilo renacentista, la de maitines, en el costado sureste, da acceso a la iglesia. Consta de arco de medio punto, con el intradós y extradós cajeados, pilares de fuste también cajeado y medallones en las enjutas. El arco se halla enmarcado por columnas jónicas de fuste estriado, que soportan el entablamento. Sobre él se dispone una hornacina de medio punto gallonada. Estrías, gallones y medallones, que ornan la portada, responden al estilo clasicista del taller, al igual que su organización en arco triunfal, inspirada en los diseños de los tratados de arquitectura. Se relaciona con otras portadas monumentales de los monasterios cistercienses gallegos, como la de la sacristía de Oseira. Las estrías e incisiones se hallan también en el dintel de la portada de la galería este del piso superior, que da acceso a la torre.

La sala capitular, hoy empleada como sacristía del templo parroquial, se abría a la galería este del claustro. De su portada con arco de medio punto -cegado- hay vestigios en el muro y sobre ella se practicó un vano rectangular. En el interior se conservó el arco, con el intradós y extradós cajeados, y en el derrame de sus pilares se construyó una alacena con puertas de madera, que todavía se mantiene. Esta obra está documentada

${ }^{56}$ Tumbo grande, f. 808 r.

«CUADERNOS DE ESTUdIOS GALLEGOS», Tomo XLIX, Fascículo 115, Santiago 2002. 
entre 1741-1742, al igual que la apertura de dos puertas - costados norte y sur (?)- y una ventana ${ }^{57}$. Se pretendía así asegurar la bóveda de terceletes y combados, muy plana y de bella traza, que cubre todo el tramo rectangular (Fig. 3a). A la fábrica renacentista también pertenecen dos vanos semicirculares con derrame, abiertos en el costado oriental, que reciben luz del patio de los Naranjos, y otros cuatro, dos a cada lado de la portada cegada, en el lienzo mural del claustro. Los arcos, casetonados como la cornisa del segundo piso de éste, y las pilastras, de fuste cajeado, apean en una repisa corrida con tres ménsulas onduladas. Próximas a ellos se hallan dos vanos rectangulares -uno con pila gallonada-, que dan luz a la estancia contigua de salida a la iglesia. En su interior las ventanas se proyectan en derrame; una de ellas, de medio punto, corresponde a una campaña anterior.

Contigua a la sala capitular se encuentra otra dependencia con bóveda de terceletes -auditorio (?)-, con acceso desde el claustro a través de una portada de arco carpanel y pilares de fuste cajeado. En su lienzo oriental se practicó, ya en la siguiente campaña de ampliación del monasterio, otro vano de comunicación con el patio de los Naranjos. Su tipología de medio punto con grueso dovelaje de sección prismática, responde a esa etapa. Así se transformaba esta estancia en un zaguán o pasadizo de comunicación (Fig. 3a). Por su costado norte se accede a una habitación, cuya cubierta, con bóveda de cañón, se prolonga a las otras dos habitaciones de ese mismo lado. Tanto la bóveda de cañón corrida como los dos tabiques de compartimentación han de corresponder a la fábrica de ampliación barroca. En efecto, los contrafuertes prismáticos conservados al exterior del patio de los Naranjos y otro frontero en el patio de Oficinas sugieren la existencia de tres bóvedas de crucería -con terceletes y quizá también con combados, de los tipos empleados en la campaña del siglo XVI-. Con estos tres tramos se rematarían las habitaciones del costado oriental del claustro, quedando así independiente el edificio supuestamente medieval, que enlaza con la muralla por el regato y foso del Prado (Fig. 5). El interior de la primera estancia contigua al mencionado zaguán abovedado, acusa muchas reformas de diversas épocas en el pavimento -compartimentado con un muro bajo de sillería transversal a la cubierta-

${ }^{57}$ Ibidem, f. $808 \mathrm{v}$. 
y en los lienzos murales, incluso con material de ladrillo. Al parecer se utilizó como prisión durante la guerra civil. En el lienzo que da al patio de los Naranjos hay huellas de un vano rectangular - puerta- tapiado. En el ángulo que comunica con el claustro se practicó otro pequeño vano de medio punto, en todo el grosor del muro, que sería el pasa platos de la cocina. Lo más probable es que en estas tres estancias se hallasen la cocina, la bodega, la panera y la despensa, al menos en el siglo XVI, por su proximidad al refectorio, aunque por esta misma circunstancia, también cabría situarla en el otro costado -noroeste-. La primera hipótesis podría confirmarse por una cita documental: la contrucción de la puerta y arco desde la cocina al Naranjal (1750-1753), que en mi opinión se identifica con la misma puerta y arco que sigue comunicando ambos patios. De todas formas la cocina debió de ser renovada en varias ocasiones, hasta que se levantó el nuevo refectorio (1789) con su cocina en la galería sur del patio de los Naranjos. Así, entre 1644-1648 se documenta la construcción de la llamada "cocina vieja», que quizá reemplazase a la del siglo XVI, y se llama así porque el autor de la noticia escribe el abadologio en el siglo XIX y termina diciendo que luego la deshizo el abad Sebastián Caballero (1704-1707) para hacer un «cuarto nuevo, el servicio para el refectorio y la despensa $»^{58}$. Otras muchas dependencias, especialmente las de los servicios del monasterio, fueron renovadas y trasladadas de lugar a lo largo de los siglos, lo cual dificulta, en la actualidad, la identificación de la mayoría de ellas.

El refectorio se sitúa, a lo largo de tres tramos, junto a la galería norte del claustro. Cabe pensar que tuviese una comunicación más directa por la cocina, al menos un pasa platos, como el que hoy se abre desde la supuesta cocina a la galería del claustro. Se cubre con tres bóvedas de crucería, con terceletes, combados y cinco claves, con motivos vegetales y cabezas de angelotes, que voltean sobre ménsulas con molduras (Figs. 3a, 7). Su acceso se realiza desde otro tramo abierto en el costado sur (calefactorio?), con bóveda de terceletes y combados y nueve claves. Otro acceso al refectorio se halla sobre un pequeño arco, practicado en ángulo sobre las dos caras de uno de los contrafuertes y parte del costado suroeste. En el lienzo mural norte de esta estancia se abren tres vanos de medio

${ }^{58}$ Tumbo grande, en YÁÑEZ NEIRA, 1974, p. 200. 
punto, con derrame al interior y exterior, que responden a la tipología de la fábrica del XVI, al igual que los contrafuertes que soportan los empujes de la bóveda. Parte de esta obra, hasta el arranque de las bóvedas, fue ejecutada por Pedro del Campo y luego terminada por otros maestros, siguiendo su traza y posiblemente con el material que aquel tenía labrado en 1581. A mitad de la altura de las ventanas hay huellas de una moldura de imposta que recorría el lienzo mural y el perímetro de los contrafuertes en retallo, disminuyendo su grosor, al menos en los tres tramos del refectorio.

El costado norte de las habitaciones del claustro se completa con otras dos estancias, cuya fábrica ha sufrido reformas importantes en los siglos XVII y XVIII, como las demás del patio de Oficinas y de la plaza de Armas. Pese a ello quedan algunos indicios de la obra original. En ellas cabría ubicar quizá la cillería, a cargo del cillero o mayordomo, que administraba la economía del monasterio y alguna estancia destinada a la compañía de soldados o puesto de guardia. Otras dependencias de servicios podrían emplazarse en esta zona o en la del patio de Armas junto a la portería: la hospedería, la enfermería de la compañía, caballeriza, etc. Su localización es problemática, pues con la ampliación del siglo XVIII hacia el Naranjal, la mayoría fueron renovadas y trasladadas a otros lugares del monasterio.

La primera habitación, con el lienzo norte abierto y bóveda de cañón, actúa de zaguán comunicando con el claustro y las habitaciones superiores. Su primitivo contrafuerte ha sufrido daños al practicarse el mencionado arco, y en esta zona se rellenó con mampostería. Cabe pensar que su primitiva cubierta fuese de crucería. Por el costado occidental comunica con la estancia de la esquina, también reformada con bóveda de cañón, pero conserva un contrafuerte en el frente occidental y un refuerzo de planta cilíndrica en el ángulo nordeste, la llamada «Torre de Vela», que sugieren el mismo tipo de bóveda de crucería para su primitiva cubierta. A ella también se accede por la plaza de Armas.

La fachada de las habitaciones de la plaza de Armas ha sufrido igualmente alteraciones. De la fábrica del siglo XVI permanecen cinco contrafuertes y la mencionada torre (Figs. 2, 3a, 8-9). Tres de ellos, los más próximos a ésta rematan en la cornisa en bisel. Posiblemente este espacio se llegase a cubrir con cinco bóvedas de crucería en la planta baja, incluyendo la de la esquina de la referida torre. La dos supuestas bóvedas más próximas a la entrada del monasterio, las de mayores di- 
mensiones, quizás ocupasen dos habitaciones. Más difícil es precisar qué estancias albergaban las otras tres bóvedas. Una parte de las supuestas tercera y cuarta bóvedas hoy se halla ocupada por la escalera barroca que sube al claustro. Sobre la puerta de acceso a ésta hay huella de un arco ojival -ya citado- que posiblemente pertenezca a la primitiva cubierta abovedada. Como ya lo indiqué, aquí permanecen vestigios de sillares medievales, y posiblemente una parte de su primitivo alzado, reutilizado en la obra del siglo XVI (Fig. 4).

La torrecilla cilíndrica, que ningún autor ha comentado, salvo Sá Bravo que la llama «torre de Vela», carece de acceso y es muy estrecha para identificarse con una garita con saeteras -torre vigia- (Fig. 2). En mi opinión se alza en un lugar estratégico y seguramente se trata de un rollo: insignia del señorío jurisdiccional del monasterio de Oia, cuya altura facilitaba su visión desde el mar. También actúa como borje-contrafuerte, reforzando los lienzos murales de los ángulos. Sobre su alzado intermedio y superior corren sendas líneas de imposta, que se prolongan sobre los lienzos murales y se interrumpe, quizá debido a las reformas posteriores -algunas ventanas- allí practicadas. El supuesto rollo remata en un friso de líneas rehundidas, como las que vimos en las portadas del claustro, y se cubre con «chapitel» o media naranja, ornado con escamas y pináculo. Su estilo clasicista le vincula con la misma campaña. En la parte inferior, junto a esta torrecilla, se alza una columna de granito con remate en bola ( $1,80 \mathrm{~m}$ de altura). Es probable que se trate de una pico$\operatorname{ta}^{59}$. Se localizaban en plazuelas o lugares públicos, donde se exponía públicamente a los culpables, «a fin de obtener la ejemplaridad de las penas», y solían tener garfios y argollas ${ }^{60}$. La de Oia, en la plaza de Armas, estaría cerca de la cárcel del monasterio (Fig. 8).

Así, pues, con esta fachada se completaba la fábrica iniciada en el claustro de las Procesiones. Veamos ahora las habitaciones del piso superior de la misma fábrica renacentista.

Desde la escalera de maitines en el costado este del claustro, los monjes subían a las celdas del dormitorio, que ocupaban el costado occidental

\footnotetext{
${ }^{59}$ Algunos rollos también se empleaban como picotas. SAMPEDRO Y FOLGAR (1942, pp. 109-111) ha identificado varios rollos y picotas en Pontevedra. Para Portugal es muy valioso el catálogo de Chaves (1930).

${ }^{60}$ SAMPEDRO y FOLGAR, 1942, pp. 109-111.
} 
y parte del oriental. En el norte cabe identificar la sala y celda abacial. Otro acceso más directo a las celdas se halla en la puerta del coro alto, abierta en el costado sur del claustro. El interior de estas habitaciones se halla muy alterado, incluso compartimentado con mucha tabiquería de ladrillo, como ocurre con toda la galería del costado oriental. Aquí cabe identificar parte de las celdas y quizá otras habitaciones cuyo destino se desconoce. Permanece la capilla de los jesuítas (ca. 1910), muy arruinada, con muros de estuco, imitando jaspeados de mármoles de colores y diseños geométricos. Aquí estuvieron los presos catalanes y en sus paredes dejaron escritas algunas notas. En el costado occidental se localiza otro grupo de celdas; la de mayores dimensiones, con balcón, podría corresponder a la del prior, que sustituía al abad en sus funciones; y en el extremo sur, acaso estuviese la enfermería de los monjes. La sala y celda abacial posiblemente llegasen a ocupar todo o gran parte del costado norte. De su mobiliario, que también es indicativo de la capacidad de las dos estancias, nos informa un inventario de 1623: una mesa francesa, un bufete de nogal y otras tres mesas. Nueve sillas francesas, más de veinte lienzos, un escritorio de nogal, dos arcas grandes, un arquetón y dos baúles, unos estantes con ciento treinta y siete cuerpos de libros, una escribanía de nogal y, para adorno de las paredes, «estiras» y cortinas $^{61}$.

En el mismo inventario figuran «catorce celdas de religiosos», contiguas a las dos galerías -este y oeste- del claustro. En ellas permanecen las ventanas abocinadas con pequeño banco corrido para la lectura y meditación de los monjes. Al exterior proyectan sencillas ventanas rectangulares con dintel y alguna puerta-balcón. En la fachada del Patio de Armas hay indicios de una balconada, que apoya sobre los dos contrafuertes, y de su posible cubierta quedan huellas de enganches bajo la cornisa. La plataforma del balcón apoya en los mencionados contrafuertes y en canes de granito, labrados con motivos vegetales y perfiles de voluta en su remate superior, que recuerdan a las zapatas que sujetan la cubierta del claustro. El remate inferior de algunos canes ofrece una figura humana y animal; su perfil y tipología parecen medievales, lo que sugiere su reutilización en la fábrica del XVI. Seguramente se han empotrado, pues

${ }^{61}$ AHN, Libro 10.220, s. f., Libro de inventario de Hoya. 1623-1807. 


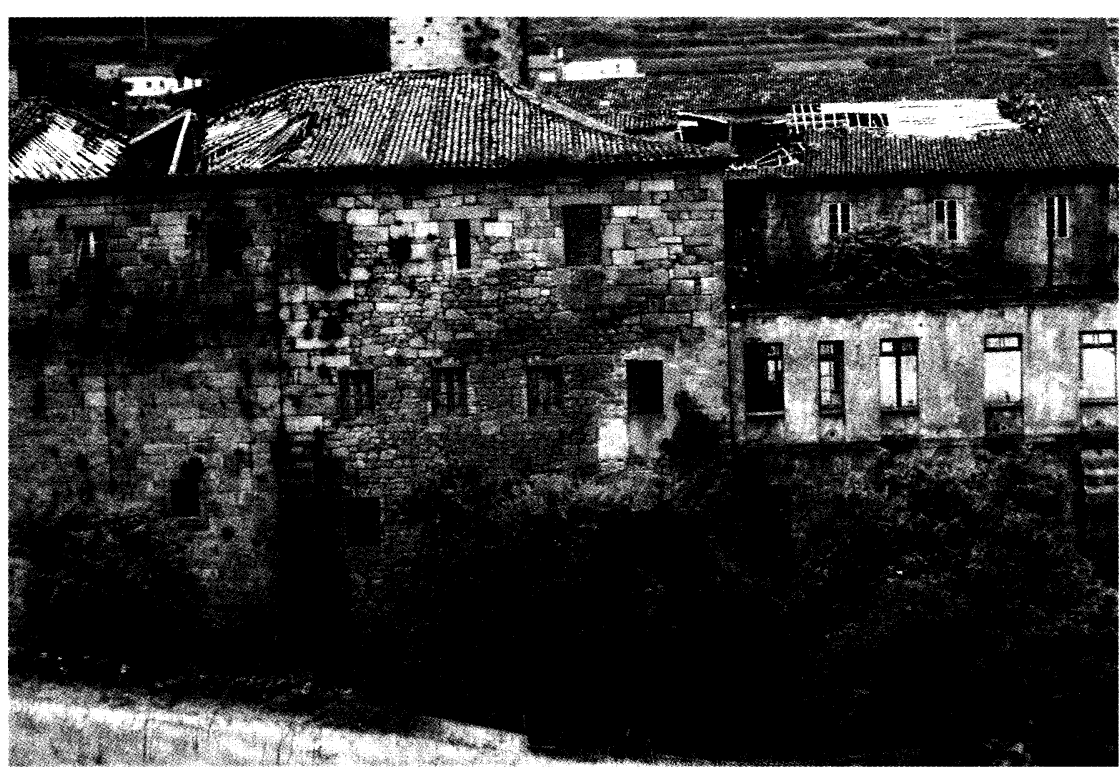

Fig. 12. Habitaciones de la galería norte y edificios anexos, con contrafuertes de la primitiva fábrica, que comunican con el Prado.

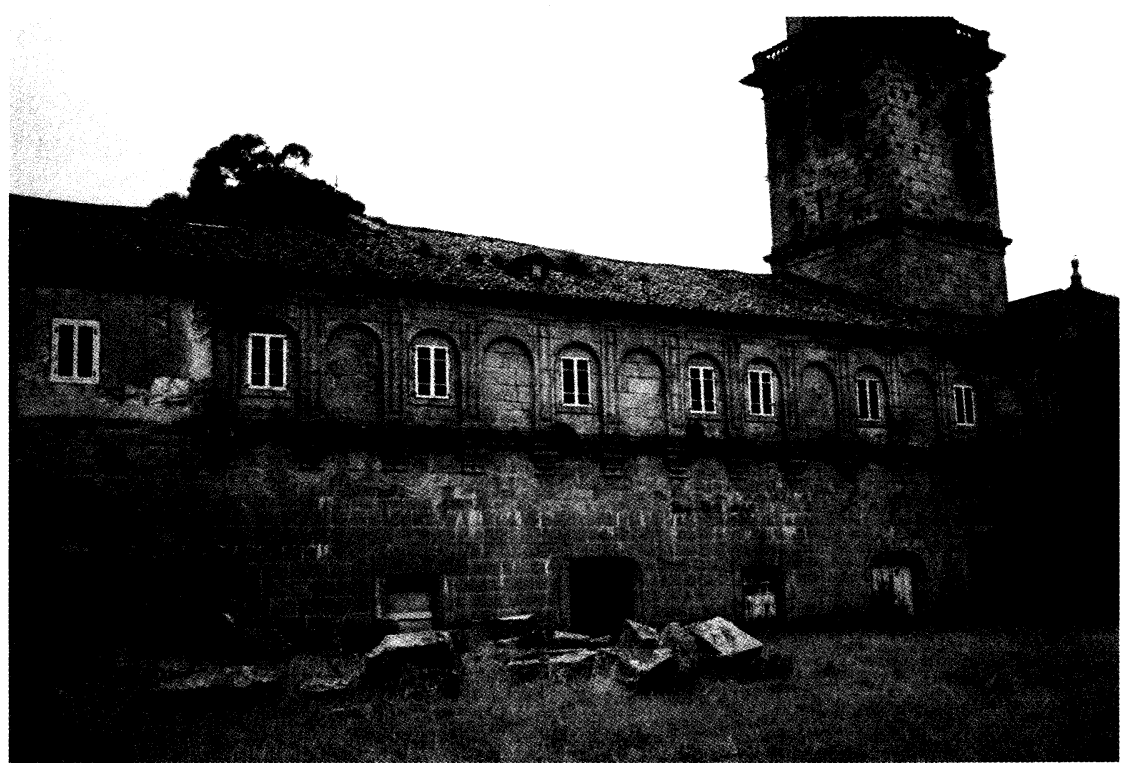

Fig. 13. Galería sur abierta al patio de los Naranjos y torre de la iglesia en el costado occidental.

«CUADERNOS DE ESTUDIOS GALLEGOS», Tomo XLIX, Fascículo 115, Santiago 2002. 


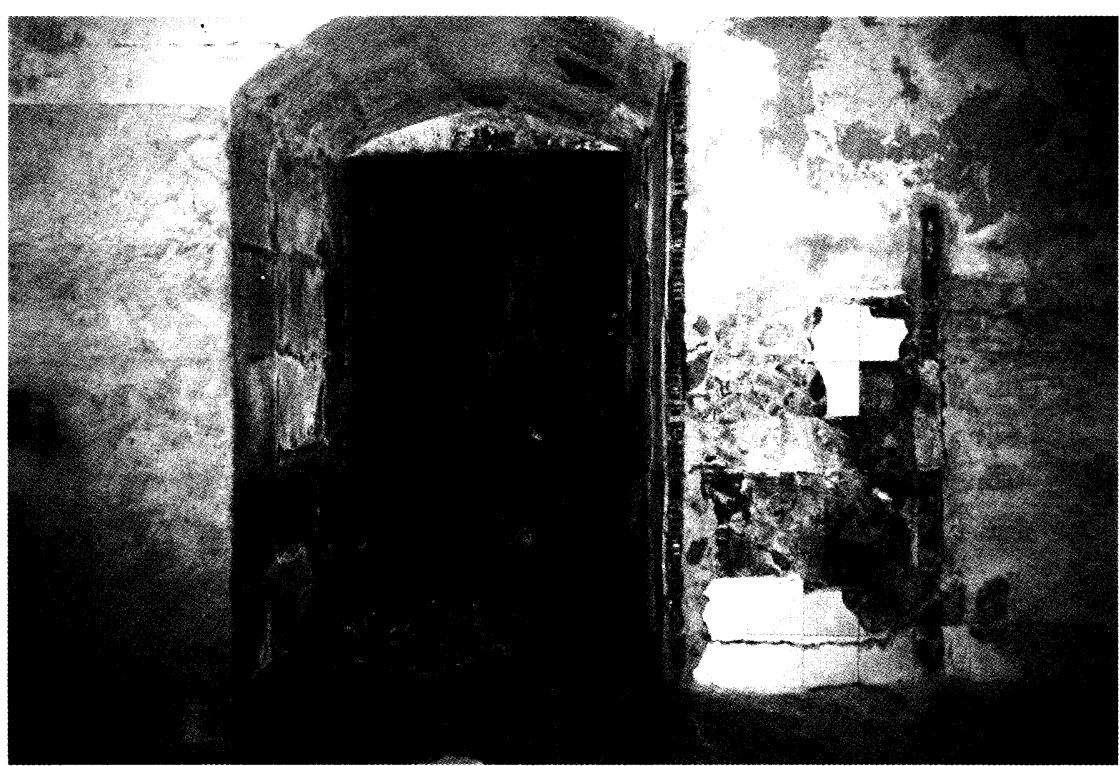

Fig. 14. Puerta tapiada, de acceso a un pasadizo, en la última habitación del costado oriental de la galería sur.

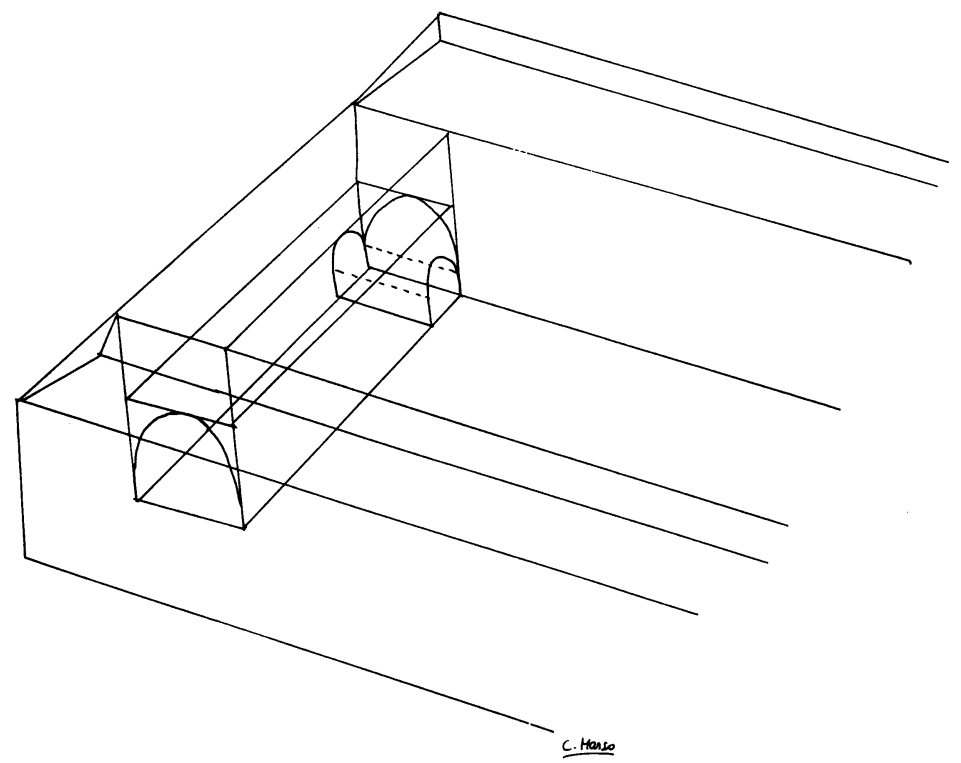

Fig. 15. Reconstrucción ideal del proyecto de cerramiento del patio de los Naranjos. Siglo XVIII.

«CUADERNOS DE ESTUDIOS GALLEGOS», Tomo XLIX, Fascículo 115, Santiago 2002. 


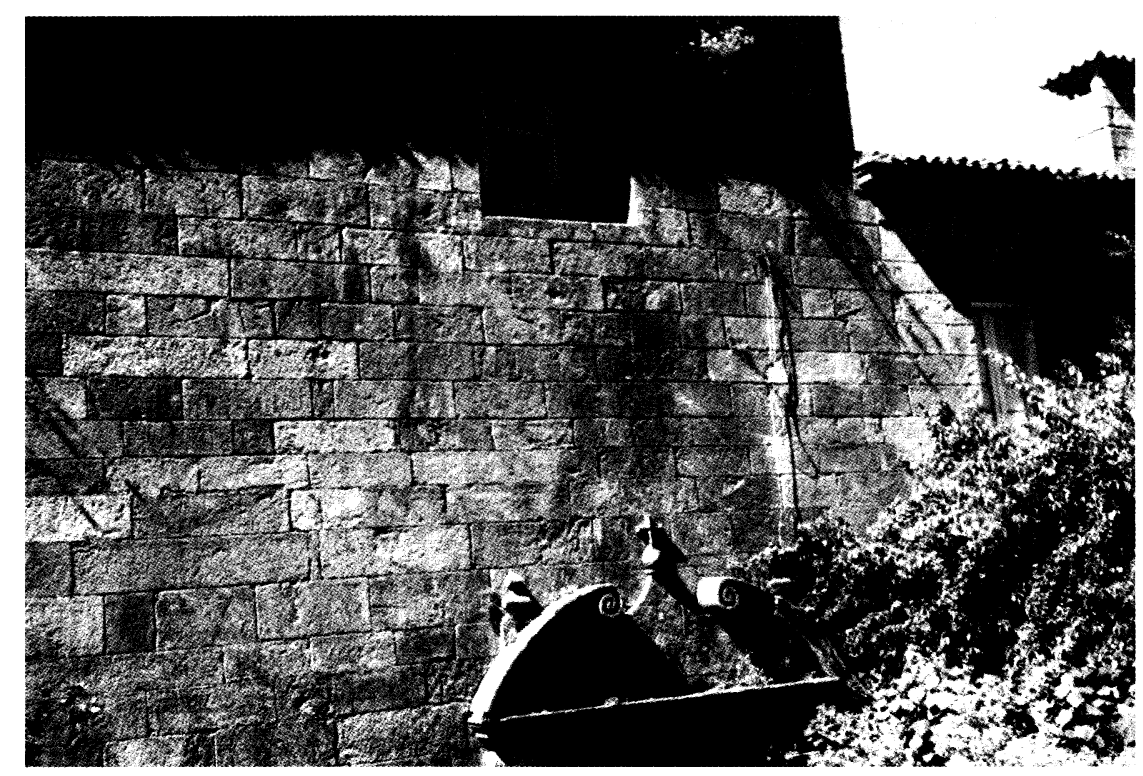

Fig. 16. Portada de acceso al patio de los Naranjos desde la Huerta a través de un zaguán abovedado.

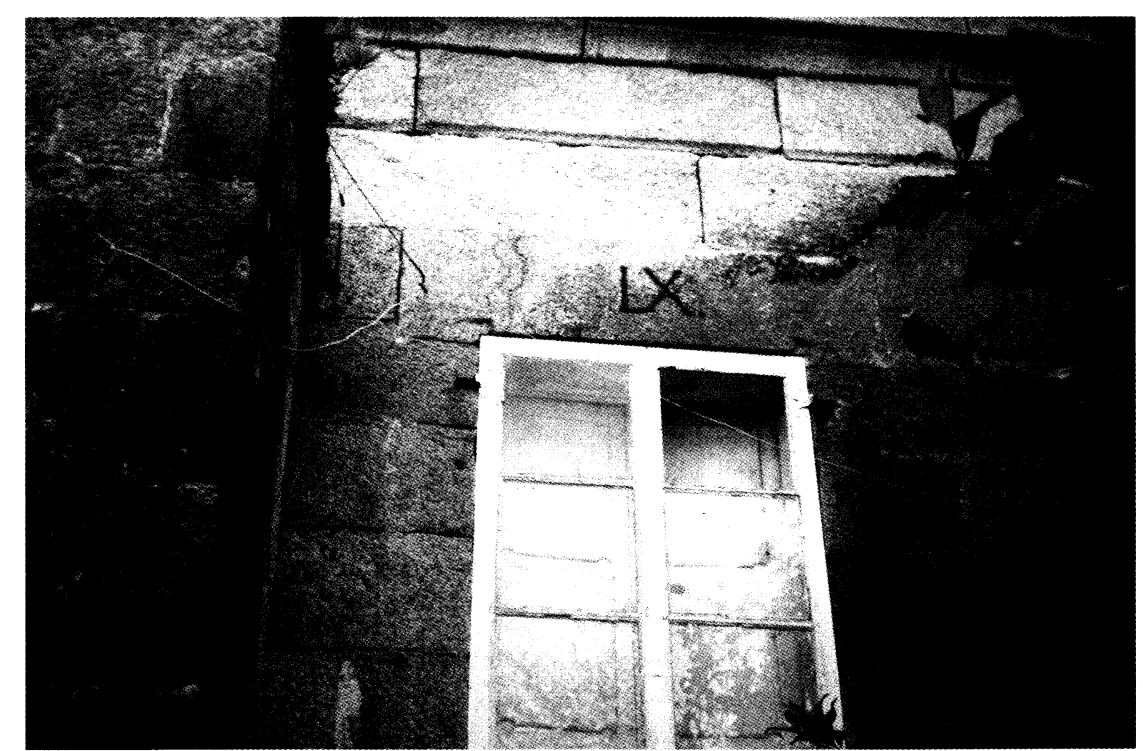

Fig. 17. Parte del epígrafe («LX») sobre el dintel de una de las ventanas que cierran la galería sur por el costado oriental. La inscripción (Año de 1768) recorre varios dinteles de puertas y ventanas de la galería sur en la fachada de la Huerta.

«CUADERNOS DE ESTUDIOS GALLEGOS», Tomo XLIX, Fascículo 115, Santiago 2002. 


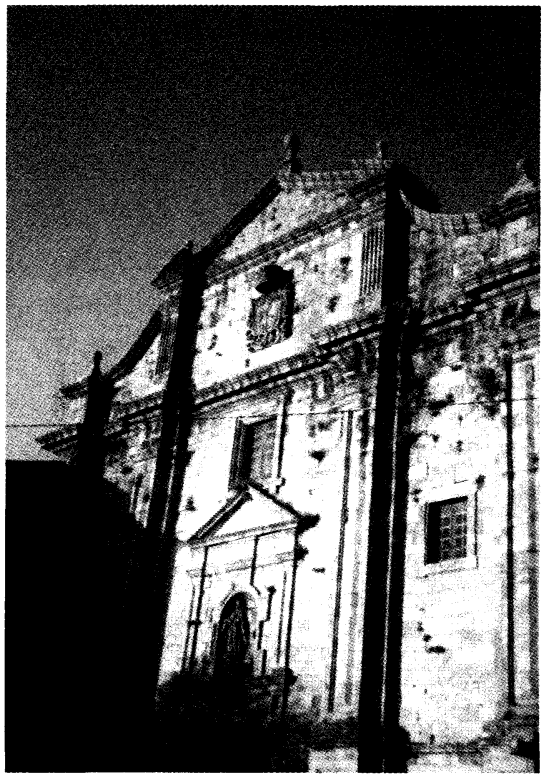

Fig. 18. Fachada de la iglesia. Siglo XVIII.

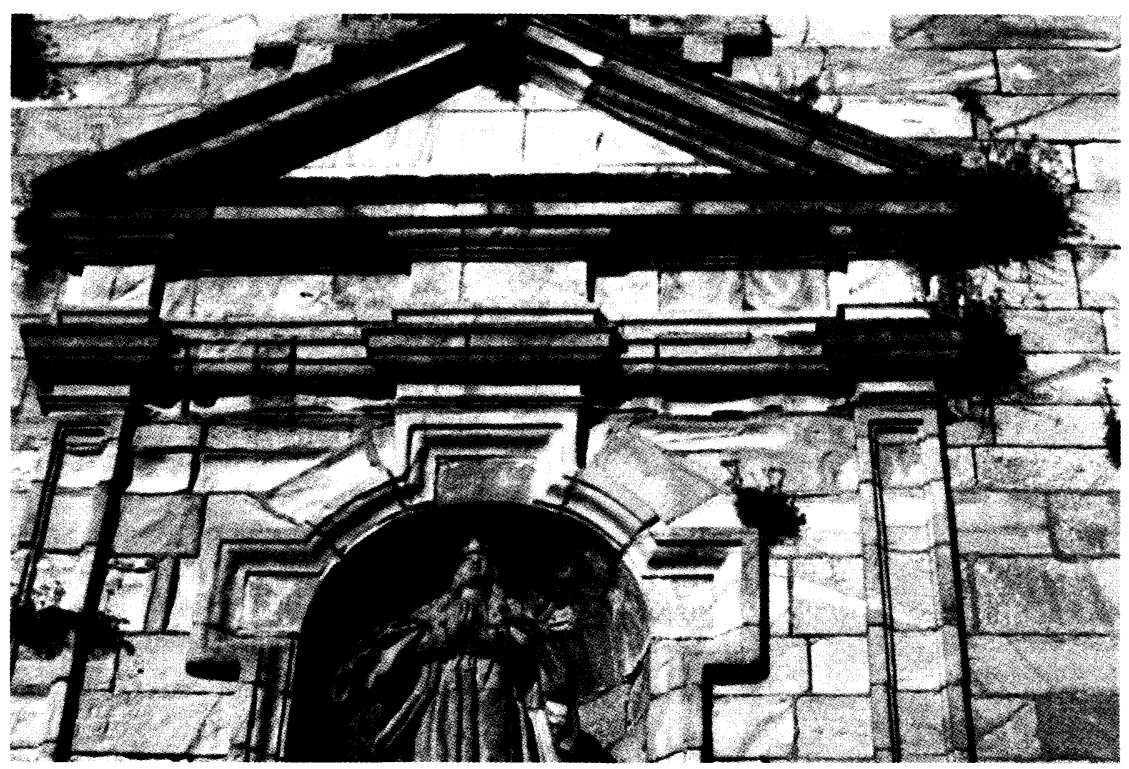

Fig. 19. Fachada de la iglesia. Detalle del frontón de la calle central con la hornacina de la Virgen y huellas de la inscripción: «Se pintó (?)» (izquierda) «Año de 1799» (derecha).

«CUADERNOS DE ESTUDIOS GALLEGOS», Tomo XLIX, Fascículo 115, Santiago 2002. 
se aprecia alguna huella. Cuando se retire la vegetación y se elimine la materia orgánica se podrá confirmar esta hipótesis. Los balaustres fueron añadidos a partir de 1910 (Fig. 9).

\section{El siglo XVII}

La documentación menciona pocas obras emprendidas en este siglo. Además de completarse la fábrica renacentista, se tiene noticia del entarimado del dormitorio (1633-1635), de la ampliación de algunas celdas (1644-1648), de la construcción de unos graneros (1677-1681) y de una bodega «a la puerta del Naranjal» (1668-1671) y de la adquisición de diversas piezas mobiliares. Pero las empresas más significativas se centraron en la fortificación del recinto. En esta época, los «monjes artilleros» se hacen célebres por sus victorias. Desde el primer cuarto de siglo, el capitán y el alférez de la compañía defensiva habitaban en el monasterio, al igual que el médico y el boticario, contratados por los monjes. La enfermería de éstos y la de la compañía fue adquiriendo importancia al igual que la botica, que en un inventario de 1820 se localiza en una de las estancias de la planta baja de la plaza de $\operatorname{Armas}^{62}$. La cárcel fue contruida entre 1660-1662.

En este siglo se levantan varias murallas del monasterio: la «de la clausura» (1620-1622), la «que está frente a la iglesia» (1650-1653), y la «que da al bosque» (1692-1695) ${ }^{63}$. La de la plaza de Armas remata en merlones con once cañoneras para la defensa de la costa. La altura de su abertura o tronera ha sido elevada unos centímetros en época reciente (Fig. 2). La misma muralla se prolonga unos metros hacia el pueblo. Otra frontera lo hace desde la fachada de la iglesia y sigue la línea de la carretera que baja al pueblo hasta enlazar con la principal. Otras cercas pequeñas se conservan en la zona pública frente a la iglesia (Fig. 9).

En el Libro de inventario de 1632 se citan «doce tiros de yerro colado», tres pequeños y nueve grandes con sus carros $^{64}$. Es posible que los grandes, con sus cureñas, estuviesen en las cañoneras del remate de la muralla de la plaza de Armas, y los pequeños en tres aspilleras o saeteras

\footnotetext{
${ }^{62}$ SÁ BRAVO, 1983, p. 138.

${ }^{63}$ YÁÑEZ NEIRA, 1974, pp. 196, 200, 205.

${ }^{64}$ AHN, Libro 10.220 , s. f.
} 
abiertas en la parte baja de la misma muralla. El acceso a estas últimas, situadas a diferentes niveles, se realiza desde el jardín de la plaza de Armas a través de una sencilla escalinata practicada en el nivel del suelo. Un primer tramo, al frente, comunica con la primera; un segundo tramo, a la izquierda, desemboca en la segunda y una pequeña rampa conduce a la tercera. El acceso se halla bordeado y protegido por una cerca de sillería, de planta cuadrada, con cuatro pequeños pilares en sus esquinas, que sobresalen unos centímetros del bloque horizontal que los une.

En esta misma etapa cabría situar otra pequeña cerca de sillería, de poca altura, con piezas verticales salientes a modo de merlones, que bordea el edificio desde la puerta de entrada hasta el patio de Oficinas, a partir de la línea frontal de los contrafuertes, y a su paso por las portadas se cierra en ángulo recto. En este espacio acotado quizás estuviese ubicado al menos una parte del jardín botánico. La documentación, dada a conocer por Sá Bravo, proporciona datos interesantes sobre las plantas cultivadas para dar servicio a la botica, los gastos de ésta, la identidad de algunos boticarios, etc ${ }^{65}$.

El muro de la portada de acceso al monasterio acusa desperfectos en su remate y retoques modernos. La puerta, con arco de medio punto y dintel de descarga, al igual que las almenas colocadas sobre la clave del arco y en las zonas próximas a él, pertenecen a una reconstrucción moderna. En efecto, en una fotografía del conjunto de hacia 1910 sólo figura una puerta de madera, con la parte superior del supuesto arco caída, y en el remate del muro no se aprecian las almenas ${ }^{66}$. Las que vemos: de una sola pieza con incisiones imitando el aparejo de sillería, nada tienen que ver con las medievales de remate triangular, que ofrecen varias piezas de sillería con juntas, como las que conservan la catedral de Tui y la colegiata de Santa María y la fortaleza de Monte Real en Baiona. De todas formas, si la cerca hubiese sido modificada en el siglo XVII, habría que pensar en merlones, como los que también se alzan en Monte Real. Para la reconstrucción de la portada es muy valioso un arranque de arco conservado cerca del muro, que sugiere la existencia de un arco de medio punto con bóveda de cañón, a modo de soportal, que daba paso a la puerta

\footnotetext{
${ }^{65}$ SÁ BRAVO, 1983, pp. 131-134.

${ }^{66}$ Reproducción en YÁÑEZ NEIRA, 1974, Lám. XVIII.
} 
de acceso propiamente dicha (Fig. 9). Esta estructura de soportal quizá tuviese algún parecido con la de Felipe IV de Monte Real (Baiona). El tipo de portada de la cerca del monasterio de Melón, enmarcada por sendas garitas y arco de medio punto con frontón, tampoco se puede descartar, sobre todo si la de Oia perteneció a la fábrica renacentista.

\section{El siglo XVIII}

Durante el siglo XVIII se emprende una nueva campaña de ampliación del monasterio hacia la Huerta y el Naranjal -así se llama en la documentación-. La epigrafía y los libros manuscritos del Archivo conventual, especialmente el tumbo grande, y el análisis estilístico facilitan el estudio de la nueva fábrica.

El proyecto del patio de los Naranjos, con dos galerías norte y sur hacia el oriente, seguramente se inició hacia el primer tercio de siglo por la galería norte. La desviación de ambas galerías ha de relacionarse con la orientación nordeste de la cabecera del templo y con el mismo desvío de su nave y claustro contiguo, que parecen seguir el curso del regato (Fig. 3a).

En el alzado inferior, la galería del norte ofrece tres ventanales rectangulares, de lisa guarnición acodada, y sendas portadas rectangulares, con guarnición acodada más resaltada. Por ellas se accede a una sola habitación cubierta con bóveda de cañón -actual granero-, que corre en sentido longitudinal -hacia oriente- y se halla compartimentada por siete arcos fajones y vanos rectangulares abocinados en el interior. En la fachada que da al Prado, la organización del alzado se proyecta en dos pisos, compartimentados horizontalmente por un friso liso de escaso resalte, que recorre su perímetro y además se prolonga en vertical actuando como descarga de los arcos fajones del interior. En sus tramos alternan ventanas rectangulares de lisa guarnición acodada con muros ciegos. En el cuerpo superior se abren ventanas rectangulares más sencillas, con una fina moldura en el dintel y en el marco, alternando dos tamaños, salvo en las dos últimas (Fig. 12).

En el lienzo mural occidental del interior de la habitación se halla una línea vertical, que delimita dos fábricas, la de mampostería, que quizá corresponda a la estancia supuestamente medieval, y la de sillería, que probablemente se levantó para cerrar las habitaciones del claustro del XVI y comunicarlas, en el segundo piso, con la galería norte del Naranjal. A ésta se accede, desde aquellas, por medio de una portada de arco de 
medio punto. Un tabique de excelente sillería, con las juntas perfectamente dispuestas, compartimenta longitudinalmente casi toda la galería en un pasillo, que mira al Naranjal, y en el amplio espacio del dormitorio. A oriente, otro tabique de la misma sillería, en sentido transversal, organiza una estancia en el remate del alzado.

El piso superior de esta galería norte figura en la documentación como la «obra del dormitorio nuevo que cae al río». En efecto, el abad fray José de Moldes (1733-1738), natural de Oia, la prosiguió «desde comenzar las ventanas asta cerrar toda la bóveda del piso» -se refiere al remate de la bóveda inferior y a la galería de ventanas que se abre al patio de los $\mathrm{Na}$ ranjos-; «y la pared a oriente la hizo enteramente desde sus cimientos». Además «compuso las celdas del dormitorio, componiendo tabiques, rebocándoles y blanqueándoles, y lo mismo hizo con los techos de dicho dormitorio, entablándolos y también el del lugar común» -la última habitación-. Para la cubierta «dejó comprada[s] y pagada[s] las vigas, quartones y tablado, y más madera necesaria para dicha obra del dormitorio nuevo, y otros materiales para dicho efecto». Su sucesor fray Sebastián de Santalla (1738-1741) se ocupó de rematarla «desde la bóveda». Asimismo «rebajó la torre del dormitorio e hizo las secretas y la librería, y lebantó, desde el zimiento, la parez que dibide las secretas de el dormitorio». También «hizo las puertas de el dormitorio» ${ }^{67}$.

Estas valiosas noticias nos permiten reconstruir las habitaciones de la galería superior: el dormitorio con las celdas y otras estancias comunes de los monjes: las secretas o letrinas, quizás al fondo de la galería, que todavía permanecen en buen estado, al menos su alzado de sillería, las portadas y los ventanales. Un epígrafe, inédito, labrado y pintado sobre el duodécimo arco del exterior: «AÑO DE 1739», confirma igualmente el remate de ambas galerías (Figs. 10-12).

Sus dos fachadas norte y sur al patio de los Naranjos ofrecen, en el cuerpo superior, sendos frisos con catorce arcos de medio punto, ligeramente rebajados y compartimentados por pilastras de fuste retundido, que se prolongan sobre el arco y sustentan un friso liso y ligeramente saliente en el que apoya la cornisa. Las pilastras apean en ménsulas, de rollo ondulado con cimacios, separadas por una línea de imposta moldurada. En

${ }^{67}$ Tumbo grande, f. $808 \mathrm{r}$. 
el interior de los arcos de la galería sur se alternan macizos y ventanas rectangulares, con marco, dintel y peana; excepto en dos arcos que ofrecen dos ventanas seguidas. En el interior de los arcos de la galería norte se practican ventanas en todos los arcos, alternando los vanos rectangulares con los de medio punto, excepto en dos arcos, que ofrecen vanos rectangulares seguidos para armonizar el ritmo con sus fronteros (Figs. 10$11,13)$.

La galería sur está adosada al ábside menor del extremo norte del templo, a las dependencias de la torre y a las habitaciones del costado oriental del claustro, en donde se practicó su acceso desde la planta superior.

Desde el patio de los Naranjos se abren a la galería sur de la planta baja seis habitaciones con puertas adinteladas y de arco carpanel, y dos vanos rectangulares en el tramo de la torre (Fig. 13). Todas ellas se cubren con bóveda de cañón en sentido longitudinal al eje de la puerta y sus ventanales reciben luz desde la Huerta. La del último tramo -horno?-, está compartimentada en dos estancias: la interior se cubre con la misma bóveda, pero en sentido transversal al eje de la entrada. Una escalera de dos tramos, adosada al muro, comunicaba con el piso superior. Su acceso al pasillo de la galería, donde hay huellas en el pavimento reformado, ha sido tapiado. En el lienzo mural oriental se halla una puerta muy abocinada, hoy tapiada con piezas de granito. Al parecer daba acceso a un pasadizo, que seguramente comunicaba con la finca llamada «El Bosque», que perteneció al monasterio (Fig. 14). En la segunda habitación se halla la bodega, con un lagar para elaborar el vino. Las otras dos habitaciones, al otro lado del zaguán de paso a la Huerta y próximas a la torre, estarían destinadas a diversos servicios del monasterio.

En los costados orientales de las dos galerías hay indicios de un proyecto para cerrar el Patio de los Naranjos con una galería transversal, que no se llegó a ejecutar (Fig. 15). En su lugar se levantó una cerca de mampostería con remate en merlones, distribuidos de forma irregular. Por su extremo sur se construyó una escalera, que comunica el Naranjal con la Huerta. Por el norte se practicó una puerta de salida al Prado (Fig. 11). Seguramente esta obra se realizó hacia mediados de siglo, cuando también se documenta la construcción de «la puerta y arco desde la cocina al Naranjal» -la que comunica con el patio de Oficinas- «y el puente del Prado», que es el que da paso a éste desde la cerca del Naranjal por el

«CUADERNOS DE ESTUDIOS GALLEGOS», Tomo XLIX, Fascículo 115, Santiago 2002. 
costado norte (1750-1753) ${ }^{68}$. Este puente, con arco de medio punto, es similar al que da acceso al Prado desde el patio de Oficinas (Fig. 3a).

Con el mencionado proyecto de cierre del Naranjal cabe relacionar al abad fray Manuel Troncoso (1753-1756), natural de Oia, que «comenzó el lienzo del Vendaval del claustro nuevo y le azimentó todo» ${ }^{69}$. Veamos lo que hoy permanece del mismo.

En el extremo oriental de la galería norte asoman los ensambles de dientes de los sillares, desde los cimientos hasta la cornisa. La última pilastra de la galería de arcos carece de fuste cajeado y la imposta se prolonga unos centímetros en ángulo recto para el supuesto cierre. Entre esa pilastra y el remate del muro se abren una ventana rectangular y una puerta-balcón (Fig. 11).

En el extremo oriental de la galería sur se reconocen más huellas del proyecto de cerramiento. Además de la prolongación en ángulo recto de la imposta en el último arco, el muro contiguo desde la altura de esta imposta hasta la cornisa se prolonga en rectángulo -casi con la misma distancia que dos arcos de galería- con material de relleno y mampostería (Fig. 13). El resto de este muro, del mismo alzado superior, se cubre con aparejo de sillería. El alzado inferior, entre las dos puertas de acceso a las estancias abovedadas, conserva el arranque de un grueso arco de medio punto, transversal al eje de las dos galerías, que seguramente comunicaría con la galería de cierre. Otro arco similar en el costado opuesto daría entonces paso a la Huerta. Sobre el arranque conservado de aquel arco, una parte del muro es de mampostería. Pero cerca de la portada de medio punto - la que da acceso a la última habitación de la galería sur- hay unas hiladas de sillería, con huellas de una probable cubierta -bóveda de cañón- para el piso inferior de la nueva galería de cerramiento, posiblemente similar a la del norte. Por otro lado, en el interior de la galería sur del piso superior, junto a la última ventana, hay claros indicios del proyecto de cerramiento: una viga de madera longitudinal y varios maderos transversales y en zig-zag con material de relleno (piedra, arenilla y cal) de unos cinco centímetros y medio de ancho, que sería el espacio destinado a la galería de cierre por este piso. La falta de recursos económicos, o en

\footnotetext{
${ }^{68}$ Tumbo grande, f. 809 r.

${ }^{69}$ Ibídem, f. $7 \mathrm{v}$.
} 
todo caso la necesidad de realizar otras empresas más urgentes, de las que tenemos noticia en la documentación, y que luego veremos, explicarían la interrupción de la obra de la galería de cierre, quizás en el mismo estado en que hoy se halla.

Las obras de ampliación debieron de continuar en la galería sur por la zona de la Huerta, que se extiende por detrás de la cabecera de la iglesia. Este costado presenta una parte más elevada en los tres tramos más próximos a los ábsides del templo. Un camino, con empedrado desde la cerca monasterial, conduce a la portada de entrada, abierta en la parte central de la galería. Presenta un vano adintelado con pilastras y frontón partido con remates en voluta, que luego se cierra en la clave rematando con una bola y una cruz. Este tipo recuerda a otras portadas de la región tudense como las dos laterales de la capilla de Santa Liberata de Baiona, muy vinculada con los monjes de Oia. La puerta da paso a un amplio zaguán con bóveda de cañón; otro vano, con arco de medio punto en su interior, se abre al patio de los Naranjos (Fig. 16).

Desde la portada de la Huerta hacia el costado sureste se localiza un epígrafe, cuyos caracteres romanos se hallan labrados y distribuidos en los dinteles de dos portadas y de cuatro ventanas, tres de ellas situadas en el muro oriental de la galería sur. El texto reza así: « $« \mathrm{~A}^{\circ} / \mathrm{D}(\mathrm{E}) / \mathrm{DCC} / \mathrm{LX}$ / V / III» (Fig. 17). Dos patines o escaleras exteriores de granito de un solo tramo - una de ellas con una galería moderna encalada- dan acceso directo a la cocina y a la galería que se abre al patio de los Naranjos (Fig. 3a). En el extremo oriental hay una pequeña balconada con balaustres de hierro; los canes y la plataforma se alzan sobre cuatro columnas dóricas. En el extremo del balcón sobresale una estancia hueca, antigua letrina. En el jardín se conserva un pozo de cantería y una pequeña fuente. Este rincón es una preciosa muestra de arquitectura popular o doméstica, pues sus estancias estaban destinadas a la zona de servicios del monasterio. El jardín fue embellecido con plantas y árboles por sus antiguos propietarios -la familia García-, que residían en esta parte del monasterio durante el invierno.

La planta superior de esta galería sur, desde su acceso por el claustro alto, ofrece un amplio corredor con nueve ventanales al patio de los $\mathrm{Na}-$ ranjos, y se prolonga en $\mathrm{L}$ hasta la salida hacia la Huerta, dando acceso al refectorio, a la cocina y a otra habitación que comunica con ellas. En el remate oriental hay tres estancias modernas -servicios- y la mencionada letrina (Fig. 13).

«CUADERNOS DE ESTUDIOS GALLEGOS», Tomo XLIX, Fascículo 115, Santiago 2002. 
El emplazamiento del mencionado epígrafe en la fachada de la Huerta permite fechar estas habitaciones en 1768 , que corresponden a una segunda campaña constructiva emprendida en la galería sur.

Además de la ampliación del monasterio en el patio de los Naranjos, durante el siglo XVIII se emprendieron otras obras importantes. Así, la renovación de la fachada del templo medieval por la suntuosa fábrica, en la que domina la corriente clasicista, que ya vimos en las galerías del patio de los Naranjos, en contraste con el barroquismo característico de otras zonas de Galicia como la fachada del Obradoiro de la catedral de Santiago, iniciada en 1738 (Fig. 18). Para Bonet Correa, la de Oia se inspira en la del Gesú de Roma, aunque se alteran sus proporciones: el primer cuerpo grandioso y el segundo más corto $^{70}$. Desde Torres Balbás se viene señalando que la fachada «se levantó en 1740, según inscripción que en ella existe ${ }^{71}$. Esta inscripción fue localizada por Bonet Correa «en su frontispicio» y señala que está «muy desgastada por la erosión» ${ }^{72}$. Folgar de la Calle, que la localiza «en dos de los sillares que flanquean la hornacina de la Virgen» y reconoce las dificultades que ofrece «su notable erosión», plantea otra posible lectura: «Se hizo» -primer sillar- y «año 1700»-segundo sillar-, en lugar de 1740. Una u otra se refieren a «alguna remodelación y no a la totalidad de la fachada». Además de admitir los paralelos estilísticos con la portada de la capilla de Santa Liberata en Baiona (1695-1701) apuntada por Bonet Correa, la mencionada autora reconoce que algunos elementos del cuerpo superior -pilastras acanaladas enmarcando el escudo y el tipo de pilastras- responden a un estilo anterior al empleado en el primer cuerpo, con enormes pilastras de fuste retundido ${ }^{73}$.

El epígrafe, en caracteres incisos, y actualmente muy erosionado por el viento y el salitre, se localiza en el lugar indicado por Folgar de la Calle. En mi opinión, en el sillar del lado izquierdo podría leerse «se pintó» (?) y en el del lado derecho «año de 1799». En este caso aludiría a una obra de policromía practicada en la hornacina y en la imagen de la Inmaculada (Fig. 19).

\footnotetext{
${ }^{70}$ BONET CORREA, 1966 , pp. 559-560.

${ }^{71}$ TORRES BALBÁS, 1954, pp. 56-57.

${ }^{72}$ BONET CORREA, 1966, p. 559.

${ }^{73}$ FOLGAR DE LA CALLE, 1998, p. 282.
} 


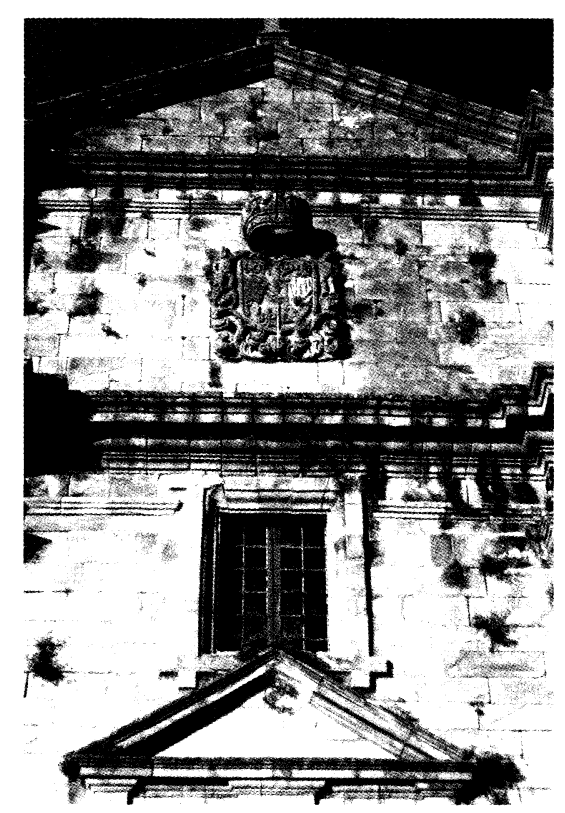

Fig. 20. Escudo de armas del monasterio de Santa María de Oia en la fachada de la iglesia.

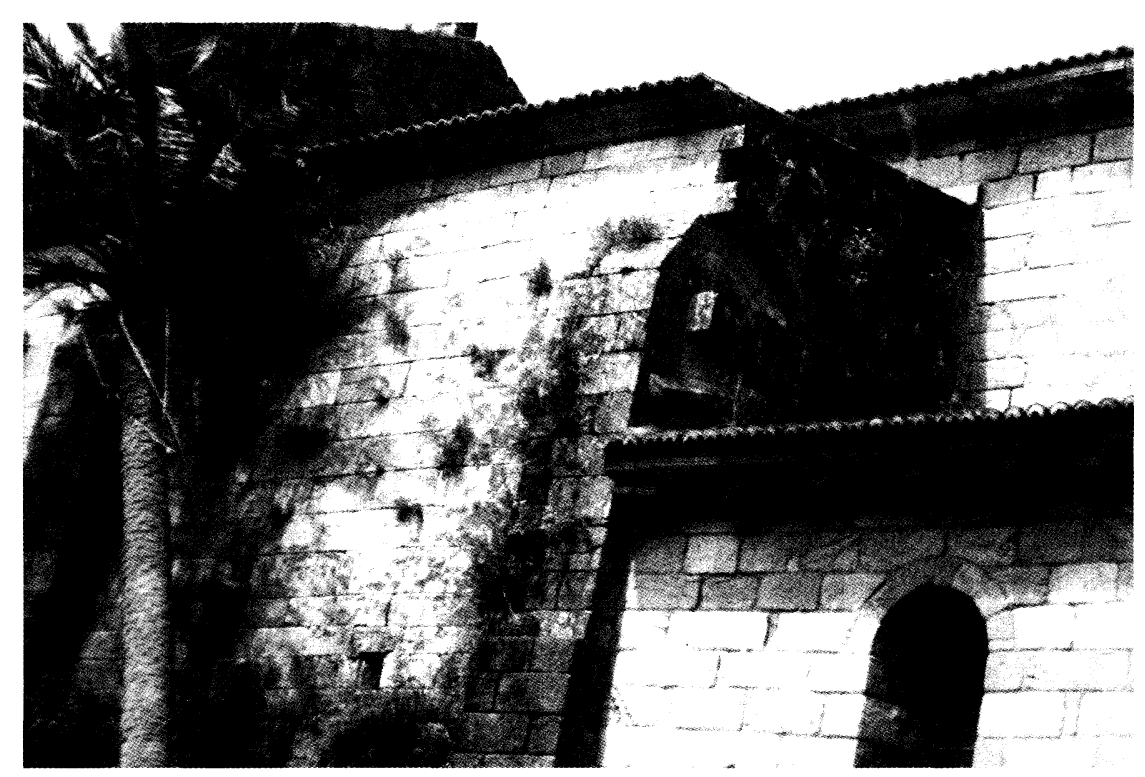

Fig. 21: Alzado suroccidental de la iglesia. Detalle de las reformas del siglo XVIII. Epígrafe: «1740».

«CUADERNOS DE ESTUDIOS GALLEGOS», Tomo XLIX, Fascículo 115, Santiago 2002. 


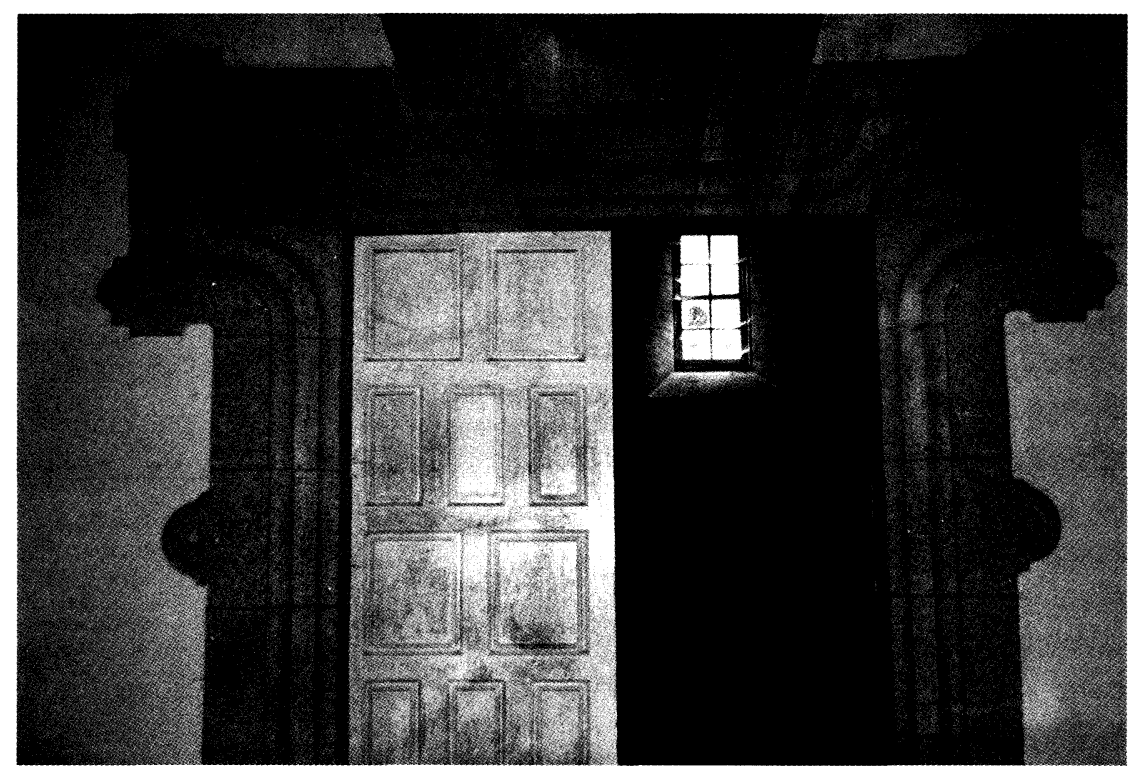

Fig. 22. Portada de acceso al refectorio de la galería sur. Siglo XVIII.

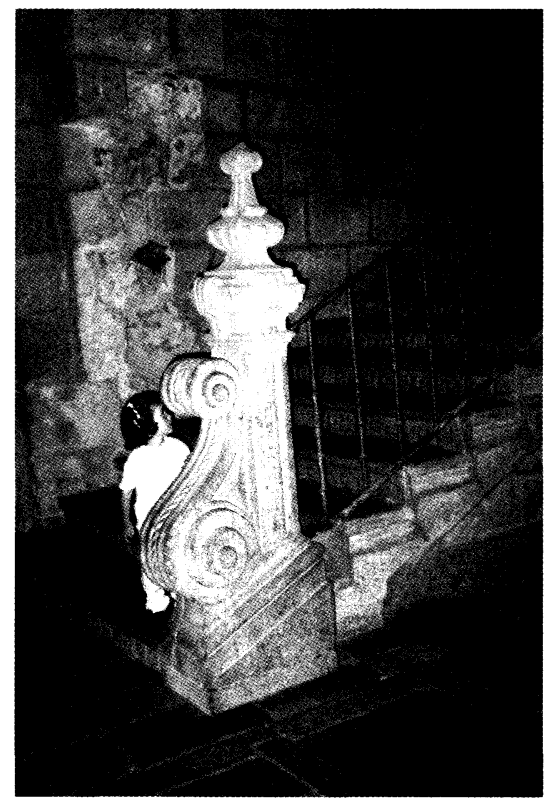

Fig. 23. Escalera de acceso a la torre desde el transepto norte de la iglesia.

«CUADERNOS DE ESTUDIOS GALLEGOS», Tomo XLIX, Fascículo 115, Santiago 2002. 
La repetida fecha de 1740, leída por Torres Balbás sin indicar su emplazamiento, quizá corresponda a la que se halla en un sillar cerca de la cornisa en el penúltimo tramo del costado sur del templo, en donde se practicaron algunas reformas sobre el alzado medieval (Fig. 21).

La documentación del siglo XVIII sobre la fachada de la iglesia, que hasta ahora no ha sido manejada para realizar su estudio artístico, ayuda a resolver algunas cuestiones. En efecto, la obra fue comenzada por el abad Ángel San Martín (1710-1713) «hasta el espejo de las bóvedas colaterales» y rematada por su sucesor Malaquías Gutiérrez (1713-1717) ${ }^{74}$. Es probable, pues, que años más tarde, quizás en 1740, se practicasen algunas reformas en la fachada, especialmente en el cuerpo inferior. Así, entre otras, la ventana de la calle central, superpuesta, con un marco excesivamente ajustado, entre la cornisa y el frontón de la hornacina.

Del primer tercio del XVIII data la nueva sacristía, contigua a la capilla mayor, de la que hay indicios en el testero exterior de ésta: una línea de arco de medio punto sugiere que se cubriese con bóveda de medio cañón -muy empleada por estos años en el cenobio-; además del muro que todavía conserva.

La fábrica de la bella torre barroca, contigua al transepto norte de la iglesia y a la galería sur del Naranjal, data de mediados del siglo XVIII. Al parecer, el abad Carlos Suárez acometió esta empresa y fray Manuel Troncoso (1753-1756) hubo de reformarla, pues «el aire auía derriuado la espadaña, veleta y coronazión $\rangle^{75}$. Su remate superior, con entablamento muy moldurado, pináculos y cúpula gallonada, pilastras de fuste retundido, enmarcadas por arcos de medio punto para el campanario, bella balaustrada y ménsulas de refuerzo con recortes placados, fue ejecutado en 1784 por el maestro Juan Lomba, vecino de A Guardia (Fig. 13) ${ }^{76}$.

El refectorio de la galería sur, levantado ese mismo año, según la inscripción ( «1784») que lleva el escudo de la cubierta con las armas de Galicia, parece reemplazar a una obra anterior, probablemente otro dormitorio, pues la documentación, desde el primer tercio y mediados de siglo, menciona la torre del dormitorio. Es muy probable que una parte de

${ }^{74}$ Tumbo grande, f. $806 \mathrm{v}$.

${ }^{75}$ Ibídem, f. $7 \mathrm{v}$.

${ }^{76}$ COUSELO BOUZAS, 1932, p. 422. 
la citada empresa de fray Sebastián de Santalla (1738-1741) en el dormitorio de la galería norte, corresponda al dormitorio de ésta del sur. Con ella cabe también identificar «un pedazo de dormitorio pegado a la torre y huerta», que hizo el abad fray Roberto Labandera (1756-1759), y «otro pedazo de dormitorio» a cargo de fray Atilano Sastre (1759-1763) ${ }^{77}$.

El refectorio ofrece un excelente estado de conservación. Un vano -pasa platos- comunica con la cocina y dos portadas lo hacen con la galería y otra estancia contigua a la cocina. Se cubre con bóveda de lunetos, con arcos fajones que voltean en ménsulas. Una línea de imposta lisa -hilada de sillares- recorre dos de los lienzos murales. En el costado que comunica con la Huerta se abren cuatro ventanas rectangulares abocinadas. El aparejo de sillería de la cubierta contrasta con el de mampostería, que cubre los cuatro lienzos. Al fondo hay una puerta adintelada con un tramo de escaleras interrumpidas y cegadas con material de relleno, que probablemente daba acceso a un púlpito. La portada de acceso desde la galería es adintelada y se decora con orejones y placas (Fig. 22). En el pavimento de granito del pasillo se conserva el dibujo de un arco con su dovelaje y al fondo una pila de agua para el servicio del refectorio, que responde al mismo estilo y época. De la cocina permanece el rincón de la «lareira» de sillería, con «cambota» y chimenea para la salida de humos, también de sillería, que asoma desde el tejado.

En el siglo XVIII se practicaron muchas reformas en las ventanas y portadas de las habitaciones que dan a los patios de Oficinas y de Armas. Así, el abad José de Moldes (1733-1738) «hizo los dos balcones de la celda y sala abacial desde los pisos, pintándolos de verde $\rangle^{78}$. Seguramente estaban unidos y cabría identificarlos en la fachada del patio de Oficinas, entre la torrecilla y los dos contrafuertes, que hoy sustentan un mirador moderno. De ellos permanecen los canes, de perfiles moldurados, que soportaban la plataforma (Fig. 2).

En el alzado inferior se transformaron asimismo las dos habitaciones con bóvedas de medio cañón y arcos de medio punto con buen dovelaje. Con el mismo tipo de cubierta y vano se abrió la comunicación hacia el Naranjal, en el costado oriental del mismo patio de Oficinas (1750-1753).

\footnotetext{
${ }^{77}$ Tumbo grande, f. 808r.

${ }^{78}$ Ibidem.
} 
Desde el punto de vista artístico, las obras más grandiosas se emprendieron en la escalera de acceso al claustro (1753-1756) y en la que sube a la torre desde el transepto norte de la iglesia (1759-1763). La de subida al claustro comunica en el primer tramo con un piso de seis celdas intermedias, con ventanas al patio de Armas, que datan de esta época. El último tramo de la escalera da acceso directo a la supuesta celda abacial y a la galería alta del claustro. Se trata de una escalera señorial, de tres tiros con dos mesetas quebradas, que se apoya en los muros, con balaustrada de granito y pilastras prismáticas -con volutas y remate en pináculos- en cada uno de sus tramos -alguno de ellos restaurado-. Recuerda a la arquitectura de los pazos barrocos gallegos y a la de otros monasterios, como el benedictino de San Clodio (Figs. 3a, 4). Señorial es también la otra escalera de acceso a la torre, de dos tramos con meseta quebrantada, balaustres metálicos, machón de arranque con voluta muy desarrollada y el frente de las escaleras labrado con almohadillado (Figs. 3a, 23).

Otras pequeñas construcciones de arquitectura doméstica se realizaron en el mismo siglo. Los dos palomares, que todavía se conservan, uno cuadrangular «frente a la Huerta», y el otro redondo, que se alza en el Prado, fueron levantados por el abad fray Roberto Labandera (1756$1759)^{79}$. Sobre el dintel de la portada del palomar circular reza el siguiente epígrafe: «Año de 1756», que confirma su construcción ese año. Fue reedificado por el abad fray Eugenio Sotelo $(1799-1803)^{80}$. Es posible que entonces se reformase la solana, bajo el alero, donde se hallan los orificios para la entrada y salida de las palomas.

En el patio de Armas hay una rueda de granito, que formaría parte de un molino de rodicio, aunque, al parecer, ésta no perteneció al monasterio. Otro molino, con una construcción de planta rectangular, sin cubierta y una rueda similar, se halla al otro lado de la carretera general, junto al recinto de «El Bosque».

En este cenobio de Santa María de Oia se desarrollaron tres estilos artísticos en su fase más pura y clásica: el cisterciense más austero, inspirado en los ideales de su fundador San Bernardo. El renacentista, con

\footnotetext{
${ }^{79}$ Ibidem, f. 809 r.

${ }^{80}$ Ibidem, f. 810 r.
}

«CUADERNOS DE ESTUDIOS GALLEGOS», Tomo XLIX, Fascículo 115, Santiago 2002. 
pervivencia de las estructuras góticas en soportes y cubiertas, pero combinado con el lenguaje herreriano en algunas portadas, soportes y elementos decorativos. El barroco del siglo XVIII, vinculado a una corriente clasicista, que prescinde de los motivos ornamentales para valorar los elementos geométricos, la superposición de planos, las líneas molduradas, las cornisas voladas y la combinación de vanos con muros lisos y la compartimentación de éstos con pilastras y molduras de imposta. El resultado es un monumento grandioso que se realza y resplandece con la belleza de su paisaje y con la serenidad que también se respira en su entorno.

\section{DOCUMENTACIÓN}

ARCHIVO HISTÓRICO NACIONAL (AHN) (Madrid): Clero. Pergaminos (Privilegios reales, bulas y escrituras de donación y foros. Desde el siglo XII. Más de 1000 piezas).

- Clero. Legajos ( ${ }^{\circ}$ 5462-5476).

- Clero. Libros (110 libros, de los siglos XVI-XIX, la mayoría de rentas y administración del cenobio y un tumbo del siglo XVII).

- Códice 60 B. Tumbo grande (ca. 1700-1832).

- Códices 1035-1038 B (Tumbos de la granja de Silva).

BIBLIOTECA DEL MONASTERIO DE OSEIRA: Algunos libros citados por H. de Sá como donados al monasterio.

BIBLIOTECA PENZOL (Vigo): Copia de Reales Privilegios y Documentos, Ms. 91.

- Monasterio de Oya. Año de 1813. Manifiesto de la verdad... Ms. 29/8.

BANCO PASTOR: Tumbo pequeño de 1739. Editado por M. Ameal González en Cistercium, 1949-1956. 


\section{BIBLIOGRAFÍA}

ALONSO ROMERO, F.: «La embarcación del petroglifo Laxe auga dos cebros (Pedornes, Santa María de Oia, Pontevedra)», Actas del XXII Congreso Nacional de Arqueología, Vigo, 1993, vol. II, pp. 137-145.

AMEAL GONZÁLEZ, M.: «El Real Monasterio de Sta. María la Real e Imperial de Oya en la provincia de Pontevedra», Cistercium, año $1, \mathbf{n}^{\circ}$ 5, 1949, pp. 112-118; año II, n. ${ }^{\circ} 7,1950$, pp. 19-22; año II, n. ${ }^{\circ} 9,1950$, pp. 83-85; año II, n. ${ }^{\circ} 11$, 1950, pp. 157-163; año III, n. ${ }^{\circ} 15$, 1951, pp. 102-109 y 218-224; año IV, 1952, pp. 97-104 y 223-227; VI, 1954, pp. 118-122 y 216-220; VII, 1955, pp. 26-29; VIII, 1956, pp. 30-32.

ARIAS, M.: «Santa María de Oya», Diccionario de Historia Eclesiástica, Madrid, 1973, t. III, pp. 107-108.

Arte del Cister en Galicia y Portugal (coord. J. Rodrigues, X. C. Valle Pérez), Fundación Calouste Gubelkian, Fundación Pero Barrié de la Maza, 1998 (en especial los estudios de J. C. Valle Pérez, M. D. Vila Jato, M. del C. Folgar de la Calle y J. M. Monterroso Montero).

ÁVILA Y LA CUEVA, F.: Historia civil y eclesiástica de la ciudad de Tuy y su obispado, (edición facsimilar), Santiago, 1995, 4 tomos (el original completo en 7 tomos en el Archivo de la Catedral de Tui. Borrador en el Museo de Pontevedra).

BONET CORREA, A.: La arquitectura en Galicia durante el siglo XVII, Madrid, 1966.

BRAUNFELS, W.: La arquitectura monacal en Occidente, Barcelona, 1975.

CHAVES, L.: Os Pelourinhos Portugueses, Portugal, 1930.

COUSELO BOUZAS, J.: Galicia artística en el siglo XVIII y primer tercio del XIX, Santiago de Compostela, 1932.

«CUADERNOS DE ESTUDIOS GALLEGOS», Tomo XLIX, Fascículo 115, Santiago 2002. 
FERNÁNDEZ RODRÍGUEZ, M.: «El monasterio de Santa María de Oya y sus maestros constructores», Cuadernos de Estudios Gallegos, XI, 1956, pp. 219-228.

FERREIRA PRIEGUE, E.: Los caminos medievales de Galicia, Ourense, 1988.

FILGUEIRA VALVERDE, J.: «Anejo. Resumen del diario de la excursión de Enrique Campo», El Museo de Pontevedra, III, 1944, pp. 161-171.

FLÓREZ, E.: España Sagrada, Madrid, 1767, t. XXII.

FOLGAR DE LA CALLE, M. ${ }^{a}$ DEL C.: «La arquitectura en los monasterios cistercienses en Galicia durante el Barroco», en Arte del Císter en Galicia y Portugal, 1998, pp. 280-327.

GAITE SANCHO, P. N.: Monumentos de Galicia. Cuadernos de Dibujos (Biblioteca del Monasterio de Poio), La Coruña, 1991.

GARCÍA ALEN, A.: «Gall. Comboa», Museo de Pontevedra, t. XXXIII, 1979, pp. 233-238.

GARCÍA CUETOS, P.: Arquitectura en Asturias 1500-1580: la dinastia de los Cerecedo, Oviedo, 1996.

GARCÍA IGLESIAS, J. M.: O Barroco (I-II), Hércules de Ediciones, La Coruña, 1993, Serie Arte, t. XIII-XIV.

GARCÍA ORO, J.: «La reforma del Císter gallego», Estudios Mindonienses, 7, 1991, pp. 659-673.

GARCÍA ORO y PORTELA SILVA, M. J.: Bayona y el espacio urbano tudense en el siglo XVI, Liceo Franciscano, XLVII, 1995.

IGLESIAS ALMEIDA, E.: Arte y artistas de la.antigua diócesis de Tuy, Tuy, 1989.

«CUADERNOS DE ESTUDIOS GALLEGOS», Tomo XLIX, Fascículo 115, Santiago 2002. 
LÓPEZ GÓMEZ, P.: «Notas sobre la propiedade do monte na provincia de Pontevedra: Os montes da xurisdicción de Oia», Xornadas Agradias Galegas, $1^{\circ}$, 1983, Santiago - I Xornadas Agrarias Galegas, 15, 16 e 17 de abril de 1983, Madrid, Facultade de Económicas da Universidade de Santiago. Servicio de Publicaciones del Ministerio de Agricultura, Pesca y Alimentación, 1984, pp. 549-563.

- «Las rentas del Monasterio de Santa María la Real de Oia en la feligresía de San Mamed de Pedornes», Boletín Auriense, XVII, 1987, pp. 243-273.

LLANO CABADO, P. de: Arquitectura popular en Galicia, Santiago de Compostela, 1981, 2 vols.

PALLARES MÉNDEZ, M. DEL C. y PORTELA SILVA, E.: El bajo valle del Miño en los siglos XII y XIII. Economía agraria y estructura social, Santiago de Compostela, 1971.

PÉREZ COSTANTI, P.: Diccionario de artistas que florecieron en Galicia durante los siglos XVI y XVII, Santiago, 1930. Ed. facsímil, Xunta de Galicia, 1988.

PORTELA SILVA, E.: La colonización cisterciense en Galicia (11421250), Santiago de Compostela, 1981.

SÁ BRAVO, H. de: Boticas monacales y medicina naturista en Galicia, León, 1983.

- El monacato en Galicia, La Coruña, 1972, 2 vols.

SAMPEDRO Y FOLGAR, C.: «Rollos y picotas de Pontevedra», El Museo de Pontevedra, t. I, 1942, pp. 109-111.

SÁNCHEZ BELDA, L.: Documentos reales de la Edad Media referentes a Galicia. Catálogo de los conservados en la Sección de Clero del Archivo Histórico Nacional, Madrid, 1953.

SÁNCHEZ CARRERA, M. ${ }^{a}$ DEL C.: El Bajo Miño en el siglo XV. El espacio y los hombres, A Coruña, 1997.

«CUADERNOS DE ESTUDIOS GALLEGOS», Tomo XLIX, Fascículo 115, Santiago 2002. 
SANDOVAL, P.: Antigüedad de la ciudad y iglesia Cathedral de Tuy, Braga, 1610. Ed. facsímil, Barcelona, 1974.

SORALUCE BLOND, J. R.: Castillos y fortificaciones de Galicia. La arquitectura militar de los siglos XVI-XVIII, La Coruña, 1985.

TAÍN GUZMÁN, M.: Los arquitectos y la contratación de obra arquitectónica en la Galicia barroca (1650-1700), A Coruña, 1997.

TAMUXE, X. M.: «Aportación al estudio histórico del priorato y granxa de San Antonio de O Rosal», Tui. Museo y Archivo Histórico Diocesano, V, 1989, pp. 235 y ss.

TORRES BALBÁS, L.: Monasterios cistercienses de Galicia, Santiago, 1954.

VALLE PÉREZ, J. C.: La arquitectura cisterciense en Galicia, La Coruña, 1982.

- «La implantación de la Orden del Císter en Galicia y su reflejo monumental durante la Edad Media», en Arte del Císter en Galicia y Portugal, 1998, pp. 3-39.

- «La restauración de la iglesia del Monasterio de Oia», Castrelos, Vigo, vol. 0, 1987, pp. 149-159.

VILA JATO, D.: Galicia en la época del Renacimiento, Hércules de Ediciones, Serie Arte, A Coruña, 1993, t. XII, cap. 1-12.

- «La arquitectura de los monasterios cistercienses en Galicia durante el Renacimiento», en Arte del Císter en Galicia y Portugal, 1998, pp. 185-229.

YÁÑEZ NEIRA, D.: «El monasterio de Santa María de Oya y sus abades», El Museo de Pontevedra, t. XXVIII, 1974, pp. 145-227.

YÁQUEZ NEIRA, D. y VALLE PÉREZ, J. C.: «Oia, Santa María de», Gran Enciclopedia Gallega, t. XXIII, pp. 24-30.

YZQUIERDO PERRÍN, R. y MANSO PORTO, C.: Arte medieval (II), Hércules de Ediciones, La Coruña, 1996, Serie Arte, t. XI. 